\title{
Identification of Potential Locations for Placement of Strategic Transformers Reserve in Puerto Rico
}

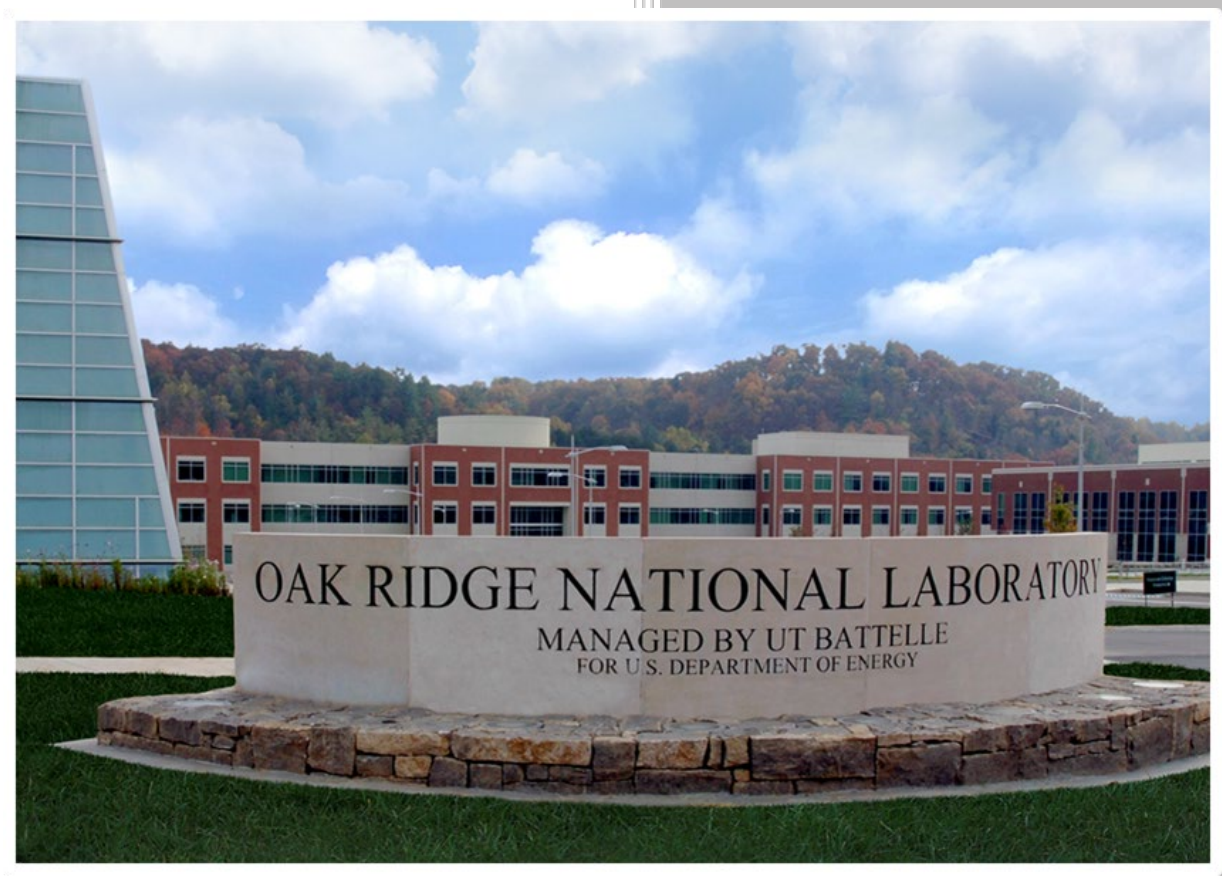

Olufemi A. Omitaomu Susan Malaso Kotikot Bandana Kar

October 2018 


\section{DOCUMENT AVAILABILITY}

Reports produced after January 1, 1996, are generally available free via US Department of Energy (DOE) SciTech Connect.

Website www.osti.gov

Reports produced before January 1, 1996, may be purchased by members of the public from the following source:

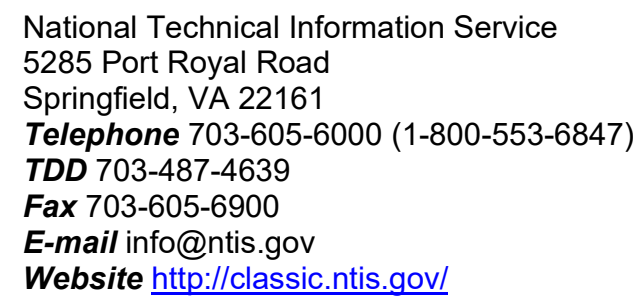

Reports are available to DOE employees, DOE contractors, Energy Technology Data Exchange representatives, and International Nuclear Information System representatives from the following source:

Office of Scientific and Technical Information

PO Box 62

Oak Ridge, TN 37831

Telephone 865-576-8401

Fax 865-576-5728

E-mail reports@osti.gov

Website http://www.osti.gov/contact.html

This report was prepared as an account of work sponsored by an agency of the United States Government. Neither the United States Government nor any agency thereof, nor any of their employees, makes any warranty, express or implied, or assumes any legal liability or responsibility for the accuracy, completeness, or usefulness of any information, apparatus, product, or process disclosed, or represents that its use would not infringe privately owned rights. Reference herein to any specific commercial product, process, or service by trade name, trademark, manufacturer, or otherwise, does not necessarily constitute or imply its endorsement, recommendation, or favoring by the United States Government or any agency thereof. The views and opinions of authors expressed herein do not necessarily state or reflect those of the United States Government or any agency thereof. 
Computational Sciences and Engineering Division Modeling and Simulation Group

\title{
IDENTIFICATION OF POTENTIAL LOCATIONS FOR PLACEMENT OF STRATEGIC TRANSFORMERS RESERVE IN PUERTO RICO
}

\author{
Olufemi A. Omitaomu \\ Susan Malaso Kotikot \\ Bandana Kar
}

Date Published: October 2018

Prepared by

OAK RIDGE NATIONAL LABORATORY

Oak Ridge, TN 37831-6283

managed by

UT-BATTELLE, LLC

for the

US DEPARTMENT OF ENERGY

under contract DE-AC05-00OR22725 



\section{CONTENTS}

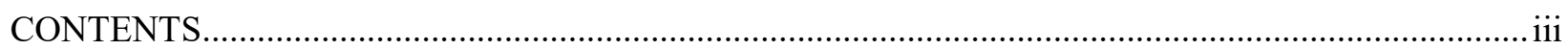

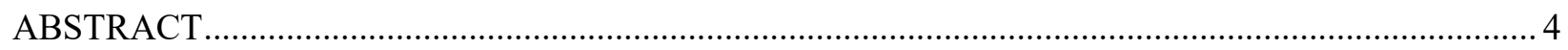

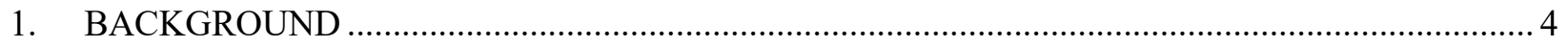

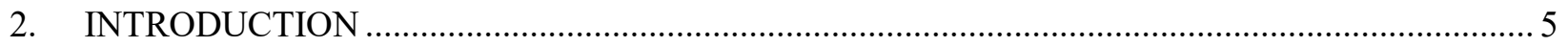

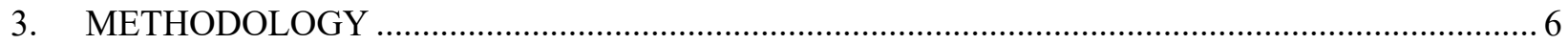

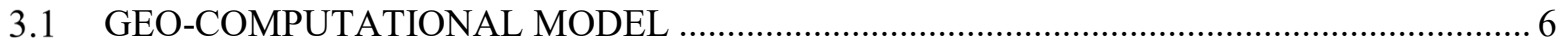

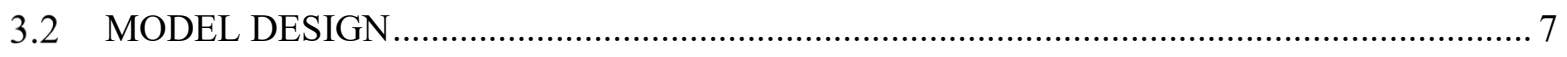

3.3 FACTORS AFFECTING PLACEMENT OF GENERATORS AND TRANSFORMERS

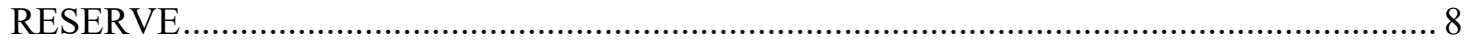

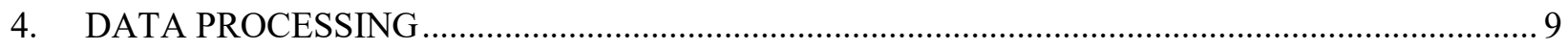

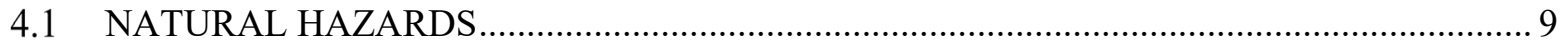

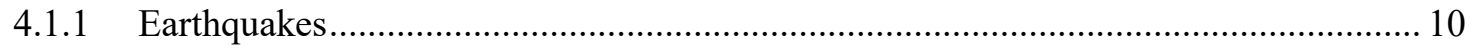

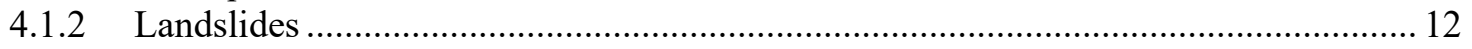

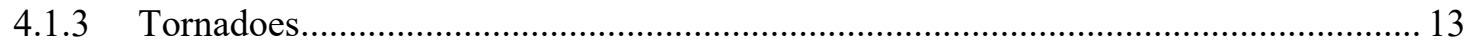

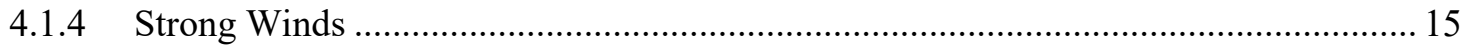

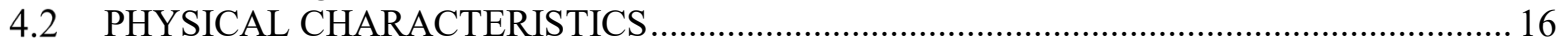

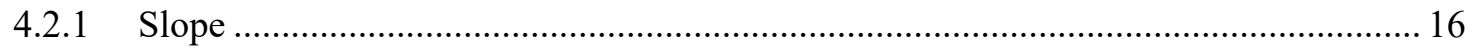

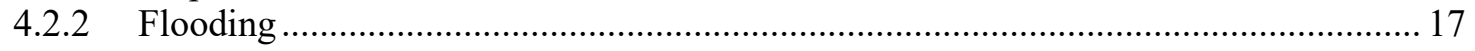

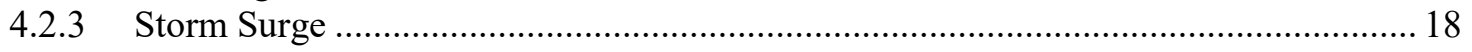

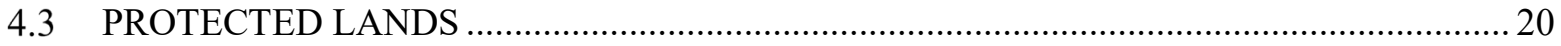

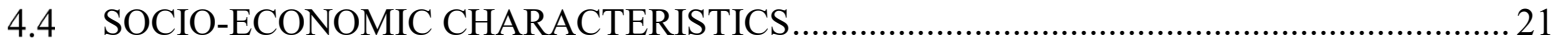

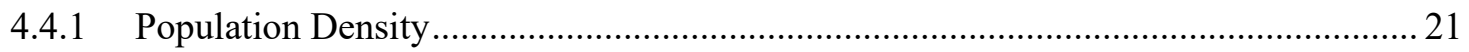

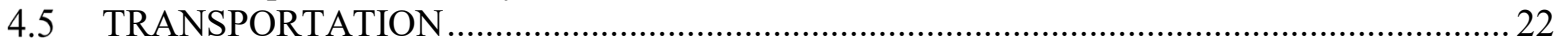

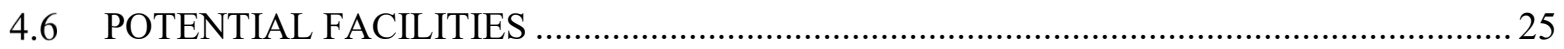

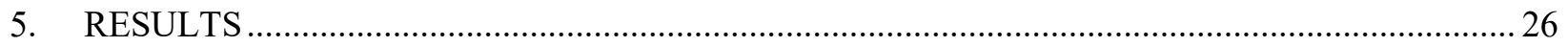

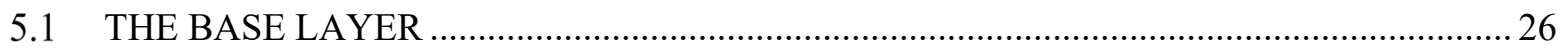

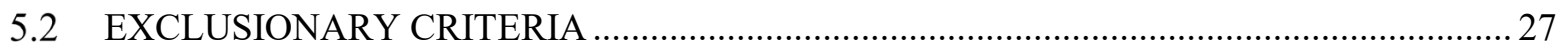

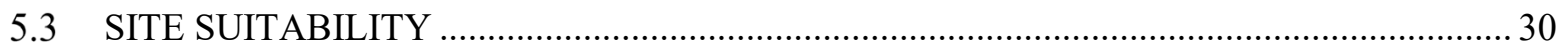

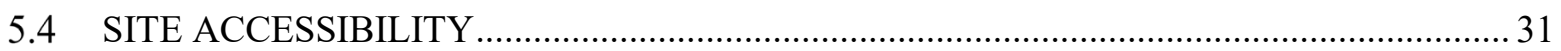

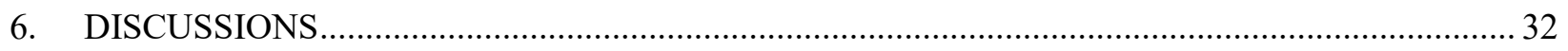

6.1 SUITABILITY OF EXISTING POWER PLANTS AND SUBSTATIONS ........................... 32

6.2 UTILIZING EXISTING CRITICAL FACILITIES............................................................... 33

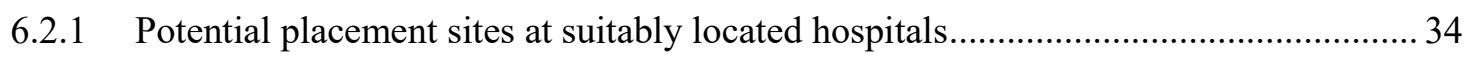

6.2.2 Potential placement sites at suitably located colleges and universities............................ 37

6.2.3 Potential placement sites at suitably located airports............................................ 37

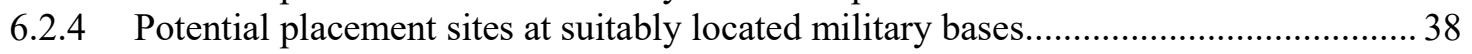

6.2.5 Potential placement sites at suitably located correctional facilities ............................. 39

6.3 ANALYZING ONLY THE VERY HIGHLY SUITABLE EXISTING FACILITIES ............. 39

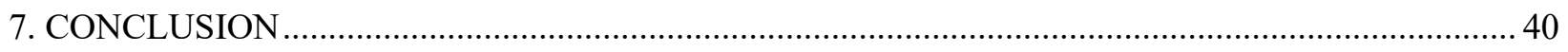

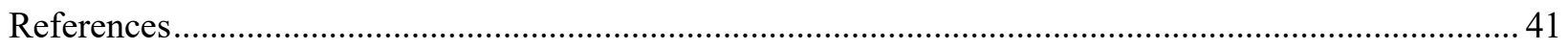




\begin{abstract}
Extreme weather events such as tropical storms cause extensive damage to energy infrastructures including generator stations, substations, poles, transformers, and power transmission lines, etc. due to their presence in hazardous locations. Often these damages lead to long term power outages as was seen in Puerto Rico (PR) following the landfall of Hurricane Maria in 2017. A potential solution to long-term power outages is strategic placement of reserve generators and transformers that would ensure continued power supply to enable restoration and recovery activities.

The strategic placement of energy storage devices requires identification of potential sites such that: (i) the damage from extreme events to energy infrastructures is minimized, (ii) power supply is optimized, and (iii) installation of these infrastructures is cost effective. To meet this goal, in this research, a MultiCriteria Evaluation technique-based site suitability analysis was implemented to identify potential sites for reserve generators and transformers in PR. To determine suitable sites and existing government facilities, the following steps were implemented: (i) identify physical, environmental, technical and socioeconomic factors contributing to site suitability; (ii) determine siting constraints based on guidelines and standards used for the energy sector (i.e., siting of nuclear plants, solar or wind farms), (iii) implement a raster data model using $30 \mathrm{~m} \times 30 \mathrm{~m}$ spatial resolution to create suitability layers for each factor, and (iv) combine suitability and exclusionary layers to create the final suitability layer.
\end{abstract}

Results show that six hospitals, four colleges and universities, and five correctional facilities are in very high suitability areas and could be used to store reserve generators. These facilities are in the eastern, south-eastern, south-western, and southern part of the island except for one correctional facility that is in the northern part of PR. Not surprisingly, coastal areas were found to be unsuitable for siting any energy facility. More than half (55.9\%) of the island was also found to be unsuitable while only $14 \%$ of the island was found to be very highly suitable. Further assessment of current power plants and sub-stations indicated that only $16 \%$ and $42 \%$ of existing power plants and sub-stations respectively are in suitable areas. Given that the northern part of the island lacks any facility that could be used for placement of reserve generators, suitable sites identified in this region could be used for placement of storage devices.

\title{
1. BACKGROUND
}

The United States Department of Energy (DOE) is interested in identifying potential locations for strategic placement of reserve transformers, generators, and mobile substations in PR to expedite restoration of power in the event of power supply disruptions. Major disasters in the United States have caused extensive damage to energy infrastructures including generator stations, substations, poles, transformers, power lines, and others. The result is long-term power outages and slow recovery in some areas, such as PR following Hurricane Maria in2017. Identifying potential locations to strategically place stockpiles of spare transformers and other essential grid equipment are therefore considered a viable option to ensure power availability to customers, and for restoration and recovery activities. To meet this goal, it is essential to identify candidate sites suitable for this strategic placement of extra essential grid equipment. The Oak Ridge National Laboratory (ORNL) has been tasked with the development of a workflow to identify suitable sites in PR. For this project, ORNL is leveraging the existing capabilities available in Oak Ridge Siting Analysis for power Generation Expansion (OR-SAGE) (Omitaomu et al. 2012). The OR-SAGE technology was developed at ORNL during 2009 - 2015 under the sponsorship of the Electric Power Research Institute, DOE Nuclear Energy Office, and a few utility companies. ORSAGE currently uses more than 40 datasets (e.g., population, critical assets, access to rail/barge/road, proximity to hazardous operations) in a spatially explicit decision support framework. Based on the ORSAGE framework, geospatial analysis was undertaken using different geospatial data sets to identify potential sites for locating spare transformers, generators and mobile substations in PR. 


\section{INTRODUCTION}

Following extreme events, such as hurricanes, tornadoes, earthquakes etc., energy infrastructures (e.g., power plants, power lines, transformers, and poles) experience extensive damage, which subsequently contributes to widespread power outages within the affected areas. Often, timely restoration of lost power is not possible because of (i) non-functional transportation and communication infrastructures that prohibit accessibility and initial assessment of damage, and consequently the undertaking of renovation and recovery efforts, and (ii) unavailability of any source of energy needed for initial response. It is crucial to have redundant and/or alternate energy sources following extreme events to ensure functioning of critical facilities such as hospitals and schools which are used by both displaced and injured populations. These issues have prompted a need to establish reserve generators and transformers to maintain redundancy and resiliency of energy infrastructures during extreme events. Successful implementation of the proposed geospatial strategy would: (i) ensure that energy reserve equipment provides access to power and are not impacted by extreme events, (ii) ensure power availability to most of the population including critical facilities, (iii) minimize the cost of installing reserve generators, and (iv) enable access to and from potential reserve sites to impacted areas.

Hurricane Maria of 2017 impacted the entire island of PR. As evident from Figure 1, the physical location of energy infrastructures coincided with Hurricane Maria's path of destruction. Given that most of the island was within the wind-impact zone of a category 4 hurricane, all infrastructures were severely impacted. A spatial assessment of the power infrastructures on the island after the hurricane indicated that most of the existing power plants, substations, and powerlines were greatly affected by the hurricane, and the transportation infrastructure was devastated to such an extent that restoration activities could not be performed. The result was long-term power outage throughout the island. Other than hurricanes, the island of PR is also susceptible to other extreme events, like flooding and tornadoes. It is, therefore, essential to evaluate all possible physical and social factors that may influence the siting of reserve generators and transformers with minimal to no risk of destruction. Using the OR-SAGE framework, a siting analysis was implemented for PR with the goal to identify potential sites to locate reserve generators and transformers. 


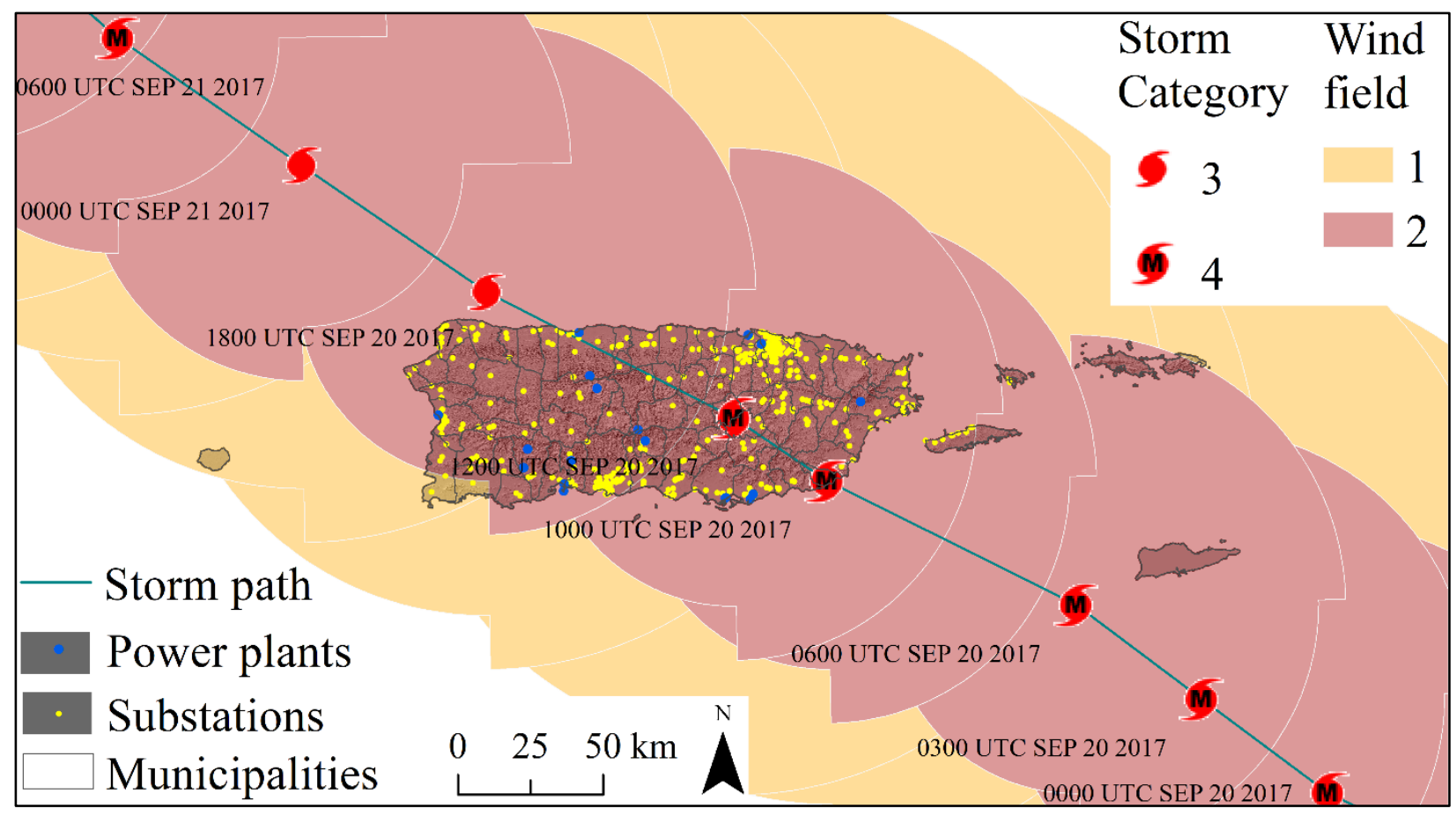

Figure 1: Relative location of current power plants and substations to hurricane Maria path.

\section{METHODOLOGY}

Assessing site suitability using the Multi Criteria Evaluation (MCE) technique and a set of factors that impact site selection is not new. Especially, MCE is used in urban planning, ecology, geography, resource conservation, and other such disciplines where several factors impact the final decision to locate certain facilities, or protect certain resources. A significant number of studies have used this technique to select sites for development purposes in urban planning (Al-Shalabi et al. 2006; Jain and Subbaiah 2007), in ecological studies to select ecotourist sites (Bunruamkaew and Murayama 2011), for locating power plants (Basri et al. 2016; Idris and Zulkiflee 2012). The general process involves assessment of physical, environmental, technical and socio-economic factors that may present conflict for placement of facilities. The inclusion and impact of factors on final decisions is determined based on a set of guidelines before combining all of the factors to determine final suitability. In the energy sector, a different set of criteria are used to decide siting of different types of power plants. For instance, guidelines for siting nuclear power plants differ from those of siting a wind or solar plant. In this study, siting criteria were identified from multiple authoritative reports, peer reviewed journal articles, books, and other published literature to determine siting criteria for reserve generators. A discussion of these criteria and their use in the analysis is presented in the following sections.

\subsection{GEO-COMPUTATIONAL MODEL}

Geographic Information Systems (GIS) based MCE is a ranking method used in conjunction with spatial data (Kar and Hodgson 2008). In this approach, spatial data layers corresponding to each factor are identified, and each data layer is then ranked according to predetermined guidelines and classified based on certain thresholds. The criteria are selected based on recommendations for suitable sites as specified in policy documents and user manuals. To a smaller degree, some subjectivity is introduced while ranking certain factors where guidelines are unavailable. Once all of the layers are ranked and classified, they are 
combined to create a base layer representing total rank (or weight). The base layer contains the cumulative scores for each location within a study site, in this case, for the entire island of PR. For ease of implementation, a raster approach was used, and the base layer using all factors was created at $30 \mathrm{~m} \times 30 \mathrm{~m}$ spatial resolution using Equation 1. Each criterion was assigned an equal rank, i.e., each factor was considered equally responsible for siting a reserve generator at a specific location.

$$
\text { Score }=\left(\sum_{j}^{n} F R_{j}\right) \text {, }
$$

where Score is the cumulative suitability score for the location, $F R_{j}$ is the factor rating for factor $j$ and $n$ is the number of factors considered. In most cases, the factors were weighted into 6 suitability levels with 0 being unsuitable and 5 being most suitable except for some factors where it was reasonable to classify them as either suitable (with a value of 1 ) or unsuitable (with a value of 0 ). These exclusionary factors were finally multiplied with the resulting base layer from Equation 1 to eliminate unsuitable locations from siting energy infrastructures. Equation 2 depicts the overall suitability score for the final output.

$$
\text { Score }=\left(\sum_{j}^{n} F R_{j}\right) \times\left(F C_{1} \times F C_{2} \times \ldots \times F C_{n}\right) \text {, }
$$

where $F C_{i}$ is a factor constraint for factor $i$ with values of 1 for suitable locations and 0 for unsuitable locations. This process may be illustrated using a schematic diagram (Figure 2) where each small square is a $30 \mathrm{~m} \times 30 \mathrm{~m}$ area on the ground represented as a pixel on a gridded layer for the factor, $F R(1,2,3 \ldots)$ or constraint, $F C(1,2,3 \ldots)$ being considered.

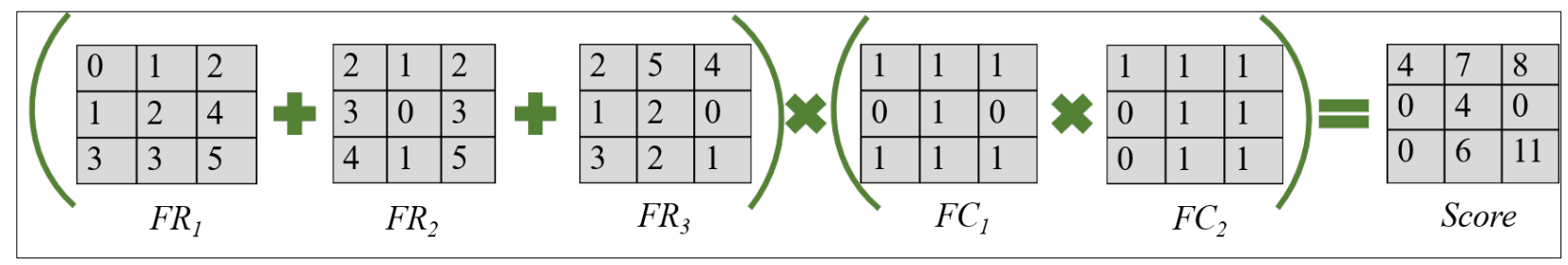

Figure 2: Schematic illustration of the GIS multicriteria approach for gridded data layers.

\subsection{MODEL DESIGN}

The modeling approach was implemented in stages to ensure that all factors are considered in determining suitable locations for the placement of power generators and transformers. Based on the guidelines, the following steps were implemented to generate the final suitability layer. Figure 3 illustrates the workflow.

i. Identify factors affecting the location of generators and transformers.

ii. Identify and obtain appropriate data representing each factor.

iii. Pre-process and curate the data into appropriate format.

iv. Reclassify each data layer based on certain thresholds.

v. Create the base layer using Equation 1.

vi. Create the exclusion layers.

vii. Generate the final suitability layer using Equation 2. 


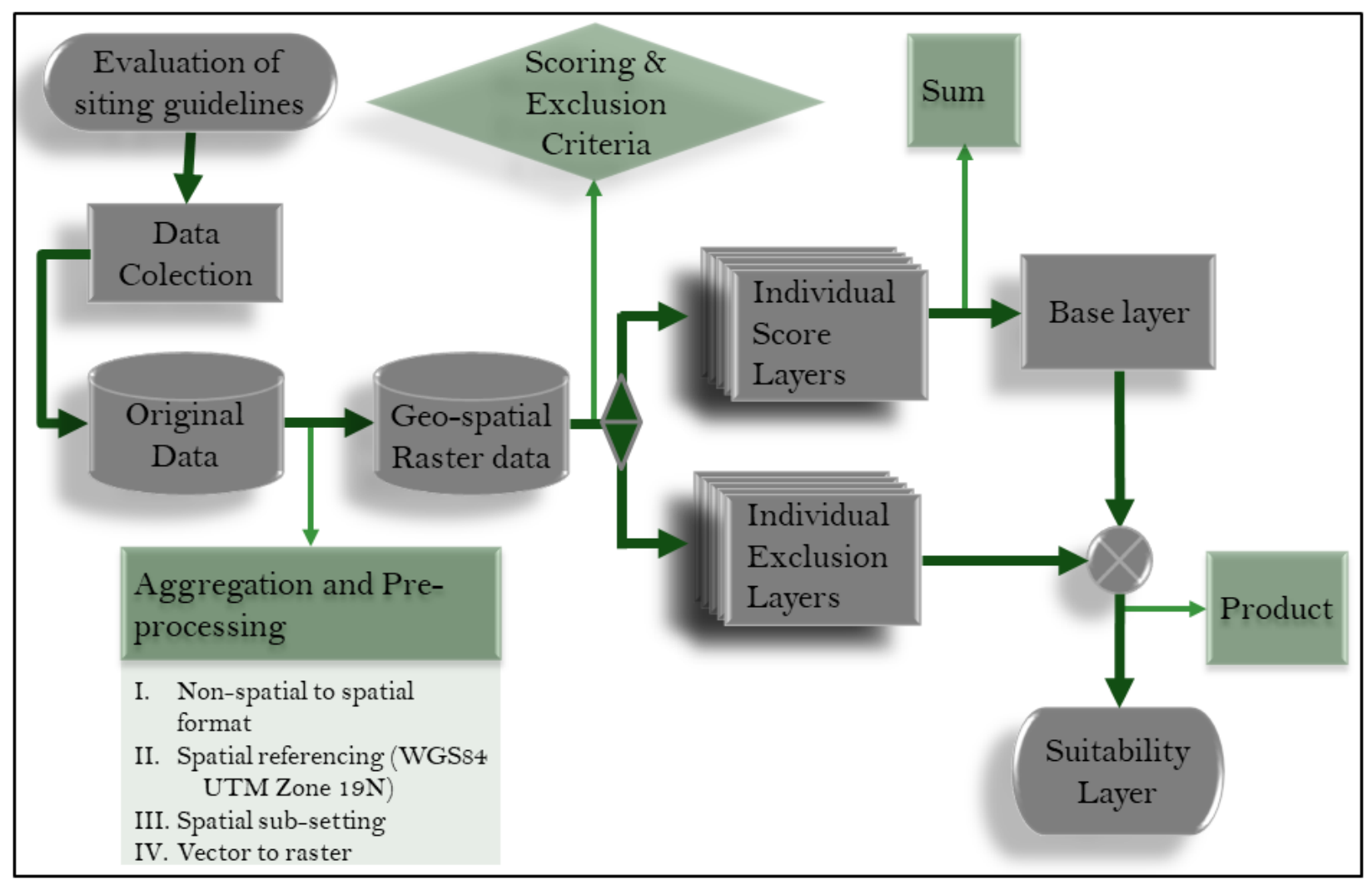

Figure 3: Project implementation workflow.

\subsection{FACTORS AFFECTING PLACEMENT OF GENERATORS AND TRANSFORMERS RESERVE}

Based on an extensive review of literature and published manuscripts, key factors were identified for consideration in evaluating suitable sites for the placement of generators and transformers. Table 1 lists the factors considered for generator siting. These factors represent risk posed by natural hazards, physical characteristics of a location, land use/cover characteristics and socio-economic conditions that influence identification of suitable sites for energy infrastructures, and transportation infrastructures crucial for moving generators to potential suitable locations at the time of need.

Table 1: Factors considered for generator siting

\begin{tabular}{|c|c|c|c|c|}
\hline & & Category & Metrics & Factor \\
\hline \multirow{3}{*}{ 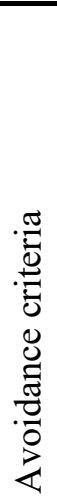 } & A & Natural Hazards & $\begin{array}{l}\text { Measure of } \\
\text { vulnerability to } \\
\text { extreme events }\end{array}$ & $\begin{array}{ll}\text { 1. } & \text { Earthquakes } \\
\text { 2. } & \text { Landslides } \\
\text { 3. } & \text { Tornadoes } \\
\text { 4. Winds } \\
\text { 5. } & \text { Storm Surge (Coastlines, Elevation) }\end{array}$ \\
\hline & $\mathrm{B}$ & $\begin{array}{l}\text { Physical } \\
\text { Characteristics }\end{array}$ & $\begin{array}{l}\text { Measure of physical } \\
\text { environmental hazard }\end{array}$ & $\begin{array}{ll}\text { 1. } & \text { Slope } \\
\text { 2. } & \text { Wetlands }\end{array}$ \\
\hline & $\bar{C}$ & Protected lands & $\begin{array}{l}\text { Measure of } \\
\text { unavailability of } \\
\text { land/assets }\end{array}$ & $\begin{array}{l}\text { 1. Parks, National monuments. National } \\
\text { Forests, Wilderness areas, Wild/Scenic } \\
\text { rivers, Wildlife refuges, American Indian } \\
\text { Reservations }\end{array}$ \\
\hline
\end{tabular}




\begin{tabular}{|c|c|c|c|c|}
\hline & $\mathrm{D}$ & $\begin{array}{l}\text { Socio-economic } \\
\text { Characteristics }\end{array}$ & Measure of land use & 1. Population Density \\
\hline & $\mathrm{E}$ & Transportation & $\begin{array}{l}\text { Measure of } \\
\text { accessibility }\end{array}$ & $\begin{array}{l}\text { 1. Roads (primary and major highways) } \\
\text { 2. Train Stations } \\
\text { 3. Sea Ports }\end{array}$ \\
\hline 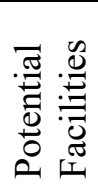 & $\mathrm{F}$ & $\begin{array}{l}\text { Potential } \\
\text { Existing } \\
\text { Facilities }\end{array}$ & $\begin{array}{l}\text { Measure of existing } \\
\text { facilities suitability }\end{array}$ & $\begin{array}{l}\text { 1. Hospitals, Colleges, Airports, Military } \\
\text { bases, Prisons }\end{array}$ \\
\hline
\end{tabular}

\section{DATA PROCESSING}

All data layers were pre-processed following either or both procedures discussed below.

a) Convert raw data to geospatial format

- Point data sets with latitude and longitude information (available in excel or csv format) were geolocated to create the geospatial data layer for each data set.

- All data sets were converted to a raster layer at $30 \mathrm{~m} \times 30 \mathrm{~m}$ spatial resolution. Because of the small size of PR, this spatial enabled representing all data and land area of PR without losing data variability and impacting computation time. Large grid sizes would have led to generalization of data sets and possible inclusion of unsuitable locations in analysis.

b) Spatial Reference System

- To ensure co-registration of data sets, all data sets were converted to the same spatial reference system - the WGS84 UTM Zone 19N.

\subsection{NATURAL HAZARDS}

All sites were screened for possible risk of following natural hazards earthquakes, landslides, storm surge, strong damaging winds, and tornadoes. Processing details for creating a suitability layer for each hazard is presented in the following section, Figure 4 depicts the workflow for creating the hazard suitability layer. 


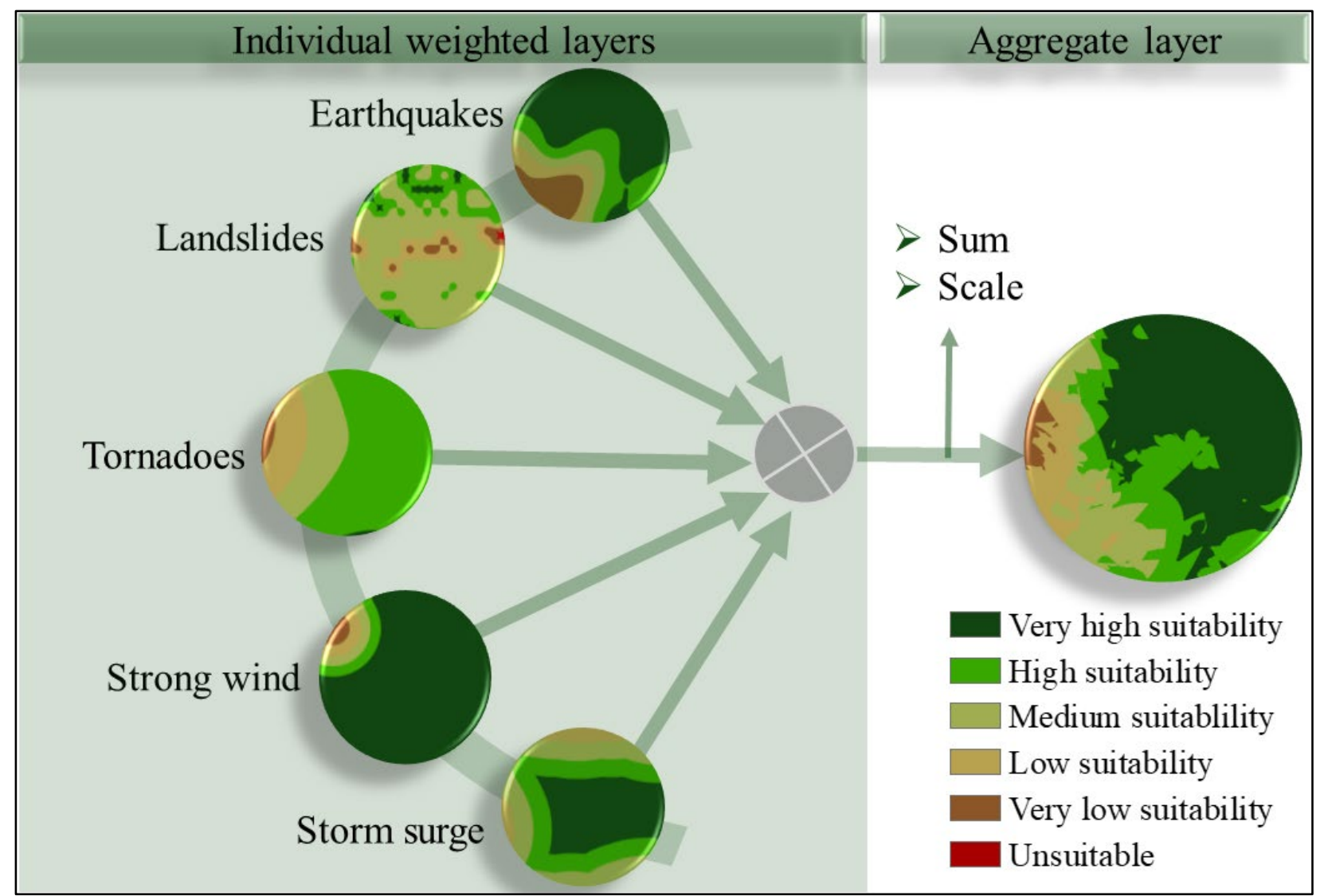

Figure 4: Processing workflow for natural hazards related factors.

\subsubsection{Earthquakes}

Earthquakes are disastrous events that often cause extensive damage to both structures and infrastructures. For this study, a dataset of historical earthquakes was obtained from the United States Geological Survey (USGS) Earthquake catalog (United States Geological Survey n.d.), which contained 120,000 earthquake records ranging in magnitude from 2.5 to 6.1 during 1950 - 2018. Given that an earthquake of magnitude of at least 3 can be felt by people in upper floors of buildings and may impact vehicles, only earthquakes of magnitude 3 or greater were considered in this study. Using 423 earthquake records of magnitude 3 or greater earthquake events (Figure 5), hotspots, i.e., locations that have experienced a high density of earthquakes during 1950 - 2018 were identified.

A kernel density function was applied to determine the density of earthquake events. The earthquake magnitude was used as weight, which ensured that stronger earthquakes were considered with greater importance than weaker earthquakes. A search radius of four miles (calculated using a spatial variant of Silverman's Rule of Thumb) was applied to define the neighborhood within which earthquake events were counted. At $30 \mathrm{~m}$ x $30 \mathrm{~m}$ spatial resolution, the output density surface represented an estimated number of earthquakes per 900 square meters. The density surface was reclassified into five suitability levels based on density range (Table 2) to obtain the earthquake suitability layer (Figure 6). The hotspots or areas with high density of earthquake events were ranked least suitable for generator siting. 


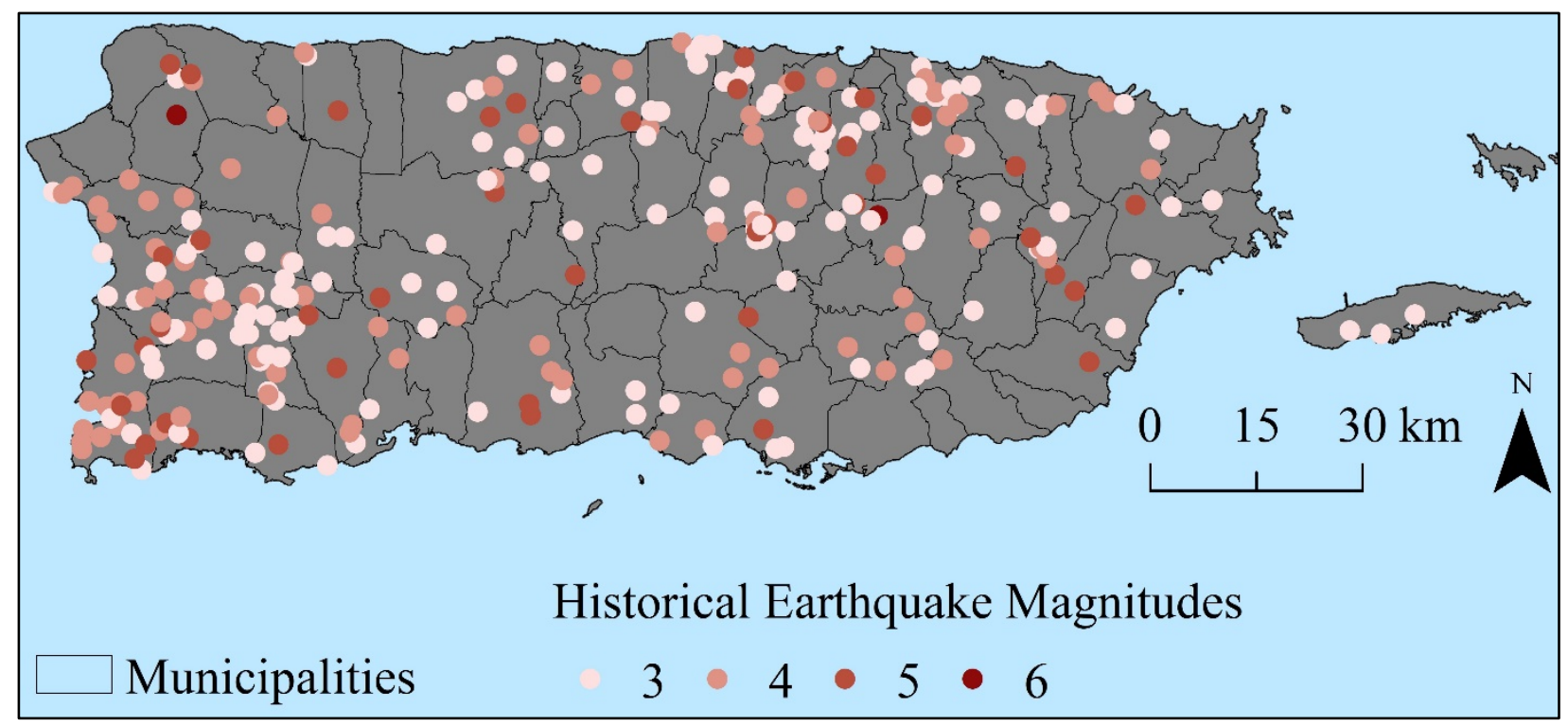

Figure 5: Point locations of historical Earthquakes of magnitude 3 and greater.

Table 2: Threshold criteria used to assign suitability levels

\begin{tabular}{lll}
\hline Value range (Densities) & Class & Suitability level \\
\hline $\mathbf{0}-\mathbf{0 . 0 7 9}$ & 5 & Very High Suitability \\
$\mathbf{0 . 0 7 9}-\mathbf{0 . 1 5 8}$ & 4 & High Suitability \\
$\mathbf{0 . 1 5 8}-\mathbf{0 . 2 3 6}$ & 3 & Medium Suitability \\
$\mathbf{0 . 2 3 6}-\mathbf{0 . 3 1 5}$ & 2 & Low Suitability \\
$\mathbf{0 . 3 1 5 - 0 . 3 9 4}$ & 1 & Very Low Suitability \\
\hline
\end{tabular}

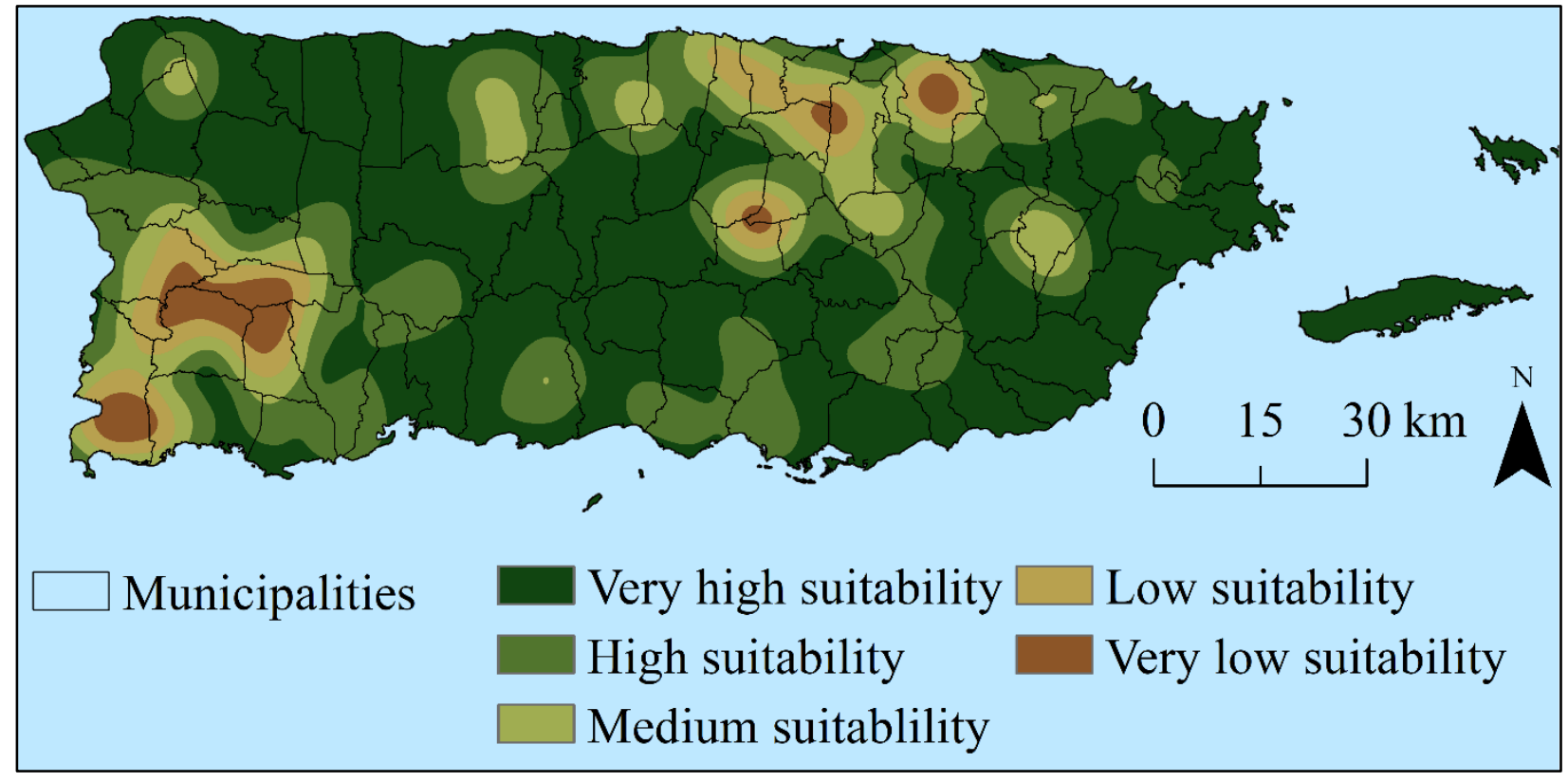

Figure 6: Suitability levels based on earthquake susceptibility. 


\subsubsection{Landslides}

Landslides are considered hazardous because of the risk of earth/mud flow that causes significant damage to infrastructures. To determine high-risk areas susceptible to landslides, a dataset (Bessette-Kirton et al. 2017) of landslide records that occurred following hurricane Maria was analyzed. The data set was obtained from the USGS Landslide Hazard Program catalog as a gridded dataset showing the number of landslides that occurred within $2 \mathrm{~km} \times 2 \mathrm{~km}$ grid areas (Figure 7). The observations were in four categories. The first category comprised locations that were not studied and therefore had no data (class code 0 ). The second category was of regions that had no landslides (class code 1). The third category comprised point locations that had less than 25 landslides per square kilometer (class code 2) and the final category was of locations that had more than 25 landslides per square kilometer (class code 3 ). Based on this data set, high-risk landslide areas are present in the central region of PR. This region was excluded from consideration as potential sites for locating generators.

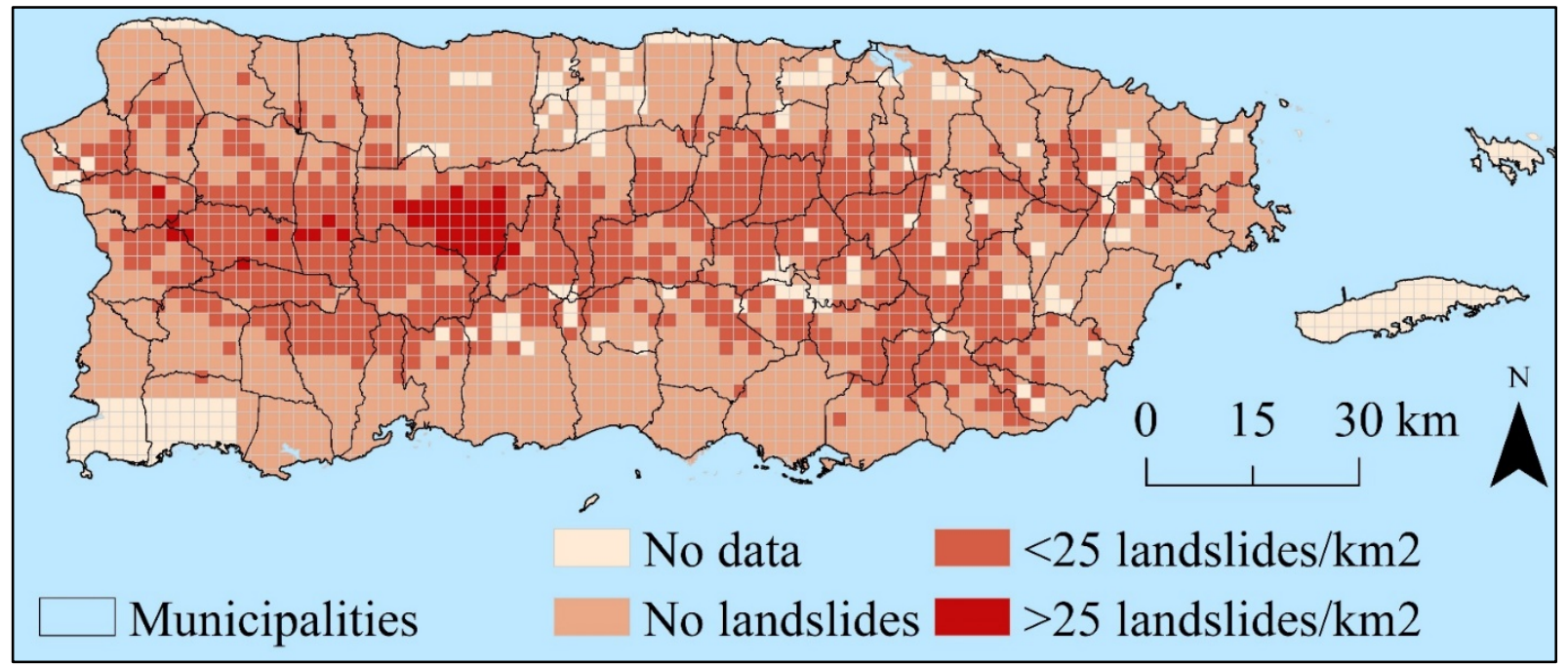

Figure 7: Landslide records as observed following hurricane Maria.

To ensure consistency in spatial resolution, a nearest neighbor algorithm was applied to the landslide dataset to transform the data into $30 \mathrm{~m}$ spatial resolution while maintaining the cell values. The resultant layer was reclassified into six suitability levels (Figure 8) according to the criteria in Table 3.

Table 3: Threshold criteria used to assign suitability levels

\begin{tabular}{lcl}
\hline Value range (Densities) & Class & Suitability level \\
\hline $0-1$ & 5 & Very High Suitability \\
$1-1.5$ & 4 & High Suitability \\
$1.5-2$ & 3 & Medium Suitability \\
$2-2.5$ & 2 & Low Suitability \\
$2.5-2.999$ & 1 & Very Low Suitability \\
$2.999-3$ & 0 & Unsuitable \\
\hline
\end{tabular}




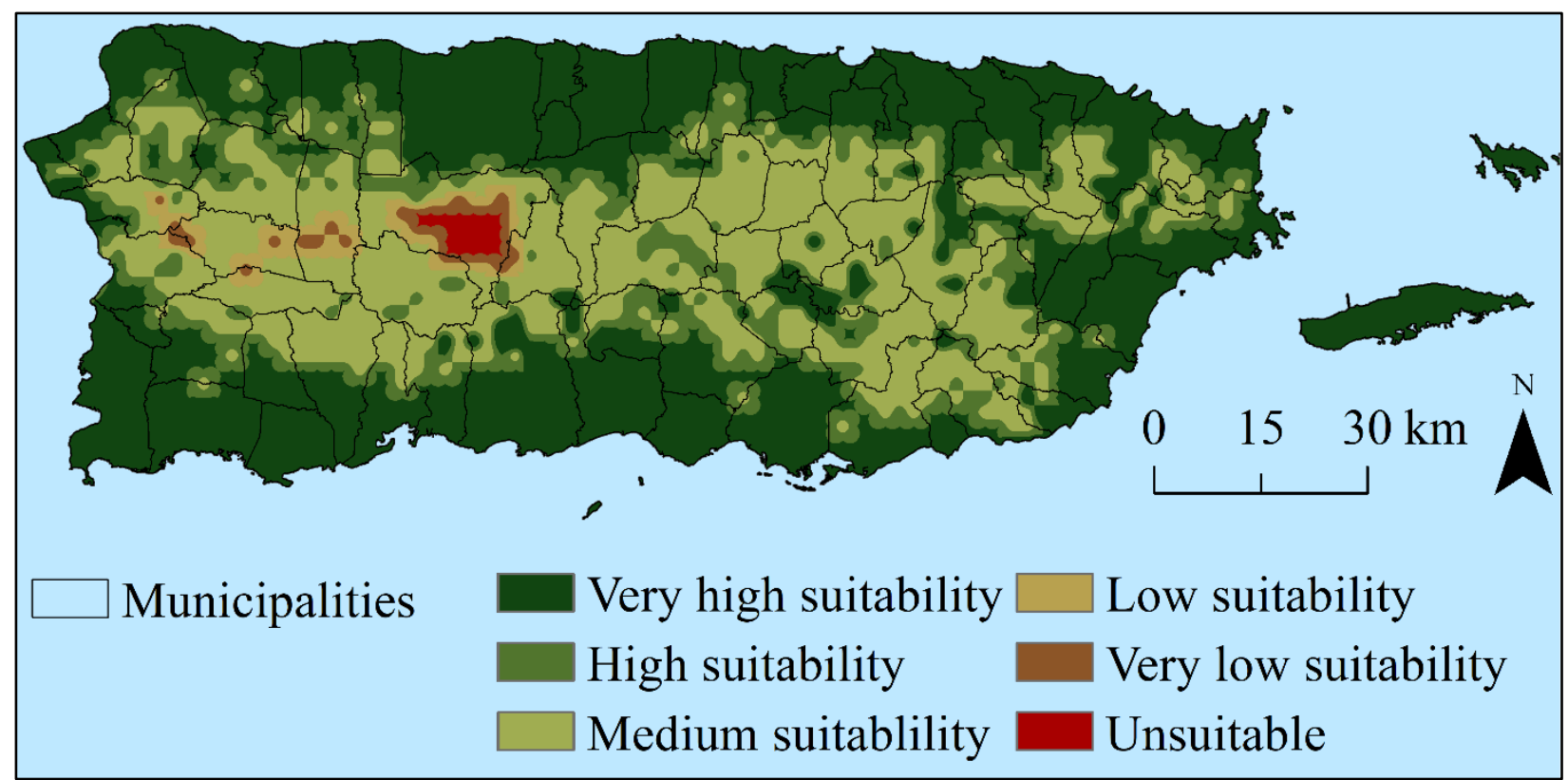

Figure 8: Suitability levels based on landslide susceptibility.

\subsubsection{Tornadoes}

An evaluation of tornado susceptibility was performed based on the observed spatial distribution of past tornadoes. Ideally, a susceptibility index is developed to delineate regions of high tornado risk based on a total assessment of atmospheric conditions that lead to a tornado. This would involve modeling atmospheric conditions coupled with long-term climate observations that are beyond the current scope. In this study, tornado susceptibility was determined by calculating the concentration of past tornado landfalls per unit area. A historical record of tornado landfalls was obtained from the National Oceanic and Atmospheric Administration (NOAA) Severe Weather Database (National Oceanic and Atmospheric Administration 2017). The data contained a record of all tornadoes that occurred during $1950-2017$ detailing the start and ending coordinates, width, attained wind speeds, and other attributes of the tornadic events. The spatial distribution of tornado landfall locations in PR is shown in Figure 9. 


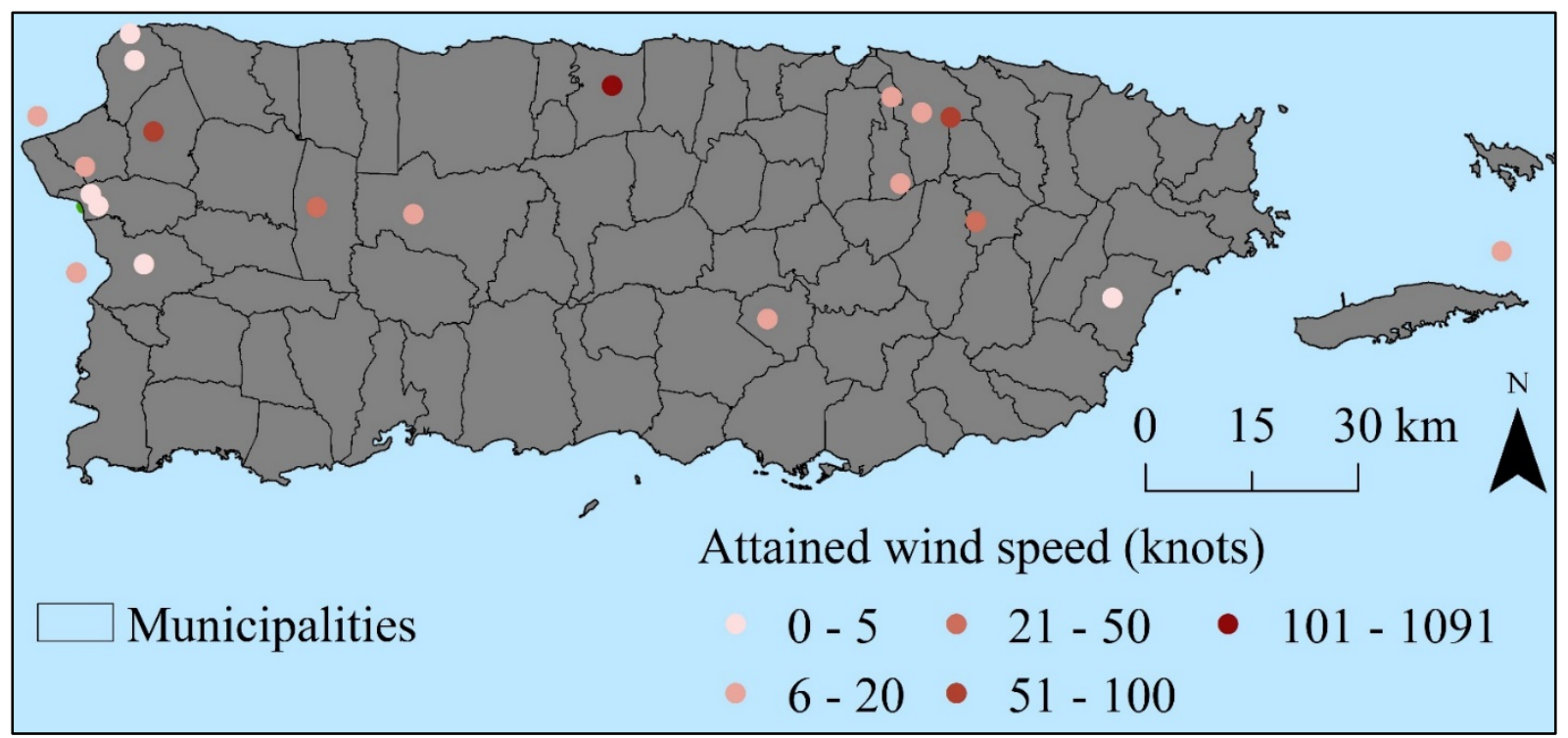

Figure 9: Historical Tornado landfall locations.

Like earthquake events, a kernel density function was applied to determine the hotspots of tornadic events at a $30 \mathrm{~m} \times 30 \mathrm{~m}$ spatial resolution. Because all tornadoes that have occurred in PR were of category EF1 (Enhanced Fujita Scale, EF Scale), all observations were weighed the same. The density layer was reclassified into 5 suitability classes (Figure 10) following the criteria in Table 4.

Table 4: Threshold criteria used to assign suitability levels

\begin{tabular}{lcl}
\hline Value range (Densities) & Class & Suitability level \\
\hline $0-0.00054$ & 5 & Very High Suitability \\
$0.00054-0.0021$ & 4 & High Suitability \\
$0.0021-0.0045$ & 3 & Medium Suitability \\
$0.0045-0.0074$ & 2 & Low Suitability \\
$0.0074-0.011$ & 1 & Very Low Suitability \\
\hline
\end{tabular}




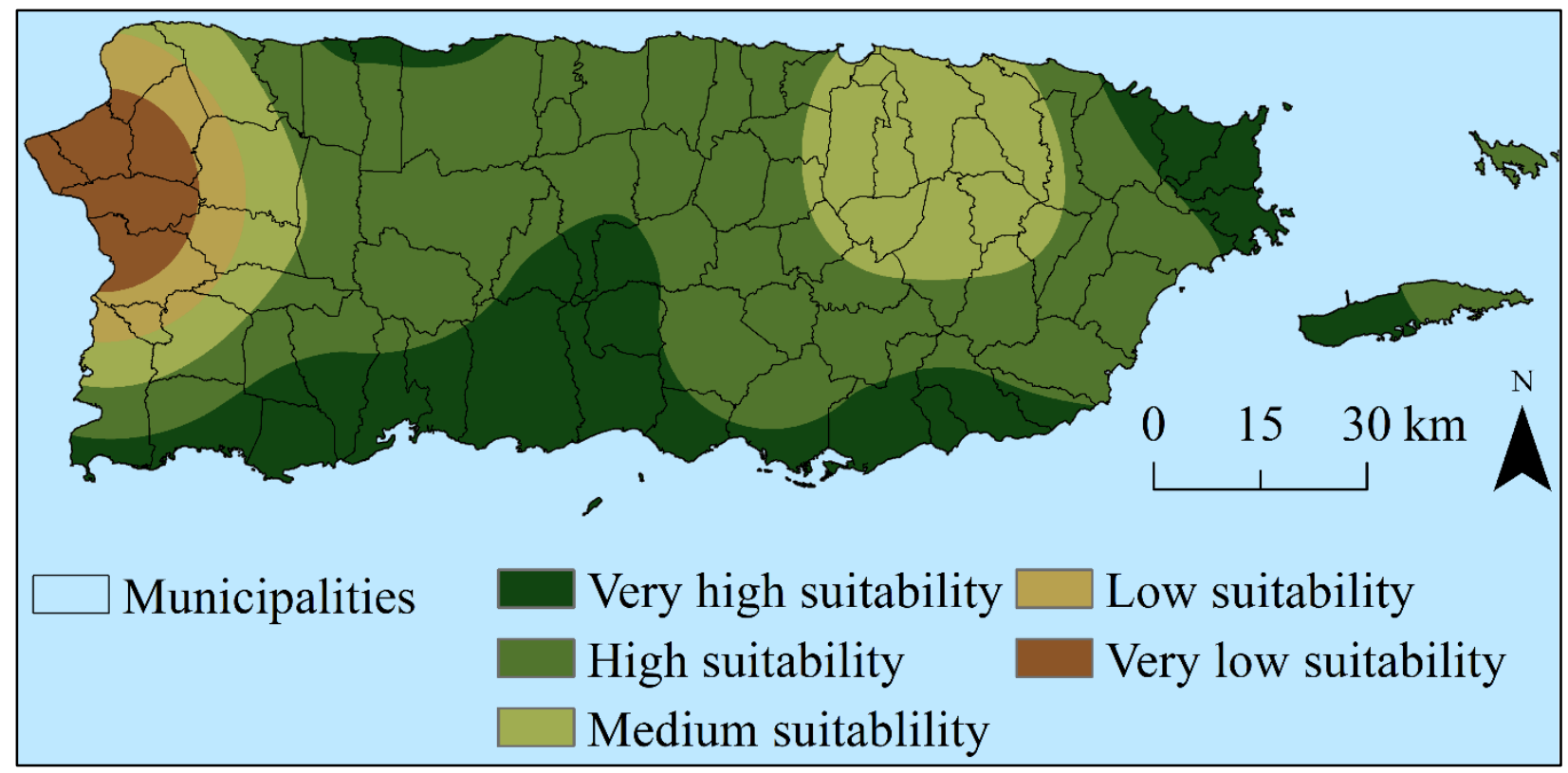

Figure 10: Suitability levels based on Tornado susceptibility.

\subsubsection{Strong Winds}

Damaging winds from storm events (straight-line winds) tend to cause falling of trees, displacement of structures and infrastructures including buildings and powerlines. Hence, it is crucial to identify areas prone to strong wind as less desirable for power infrastructure placement. A record of past strong winds for a period of 12 years (i.e., 2005 - 2017) was obtained from NOAA's Severe Weather Database (National Oceanic and Atmospheric Administration 2017). The dataset contained wind speeds ranging between $34 \mathrm{mph}$ and $61 \mathrm{mph}$, which is lower than the sustained wind speeds of an EF0 tornado (65 mph to $85 \mathrm{mph}$ ). An EF0 tornado leads to damages such as peeling surfaces off roofs, damages to gutters or siding, breaking off tree branches, or uprooting of shallow-rooted trees. The wind speed of events that have occurred in PR may therefore only lead to minor damages depending on the strength and age of buildings and other structures. Figure 11 shows the spatial distribution of historical wind events that had a wind speed greater than $50 \mathrm{mph}$.

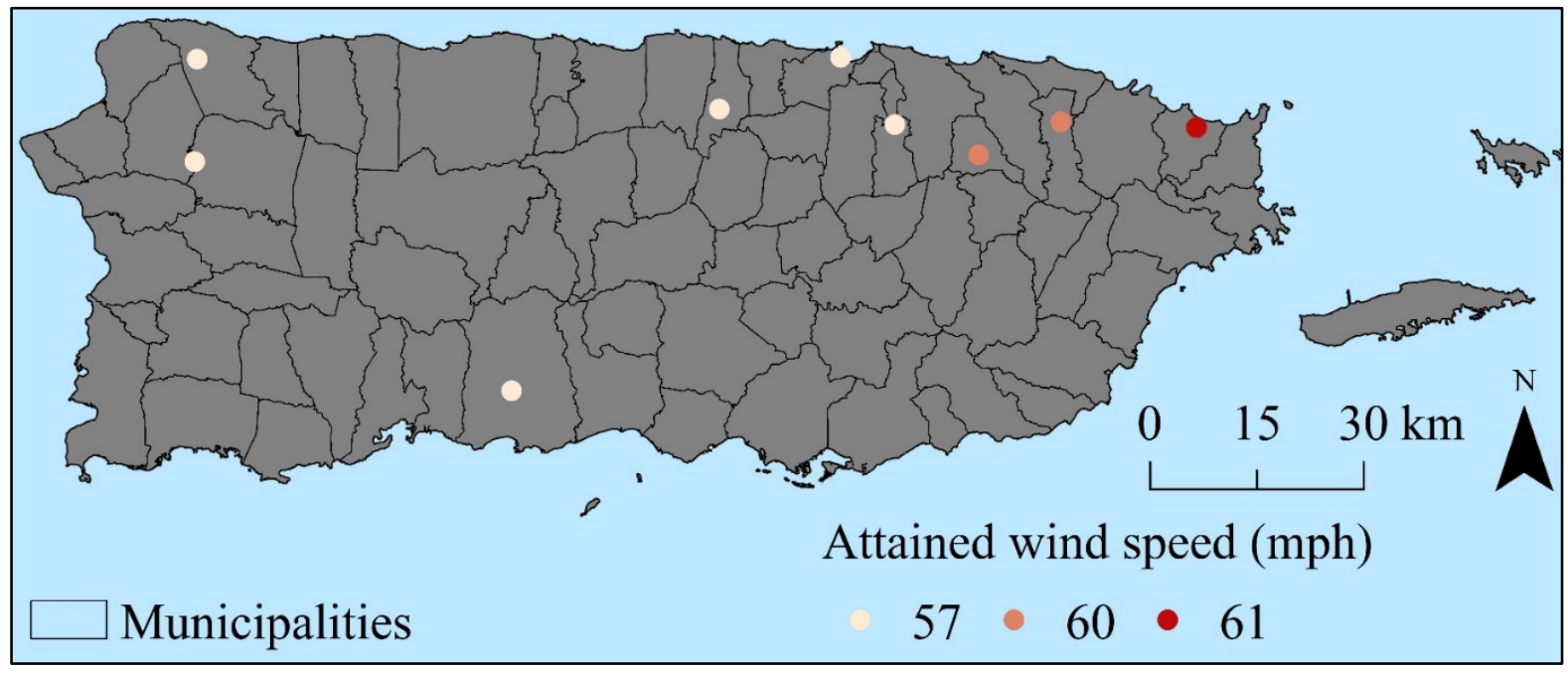

Figure 11: Historical strong wind observations. 
Based on this information, we elected to consider all wind speeds of at least $50 \mathrm{mph}$ as damaging. However, no sites were excluded based on the winds, but a ranking was performed giving less preference to locations close to stronger winds. Using the record of wind speeds greater than $50 \mathrm{mph}$, density analysis was done with the wind magnitudes as weights, and the density layer reclassified into five suitability levels following criteria specified in Table 5 to obtain the suitability layer in Figure 12.

Table 5: Threshold criteria used to assign suitability levels - strong wind

\begin{tabular}{lcl}
\hline Value range (Densities) & Class & Suitability level \\
\hline $0-0.043$ & 5 & Very High Suitability \\
$0.043-0.131$ & 4 & High Suitability \\
$0.131-0.221$ & 3 & Medium Suitability \\
$0.221-0.311$ & 2 & Low Suitability \\
$0.311-0.421$ & 1 & Very Low Suitability \\
\hline
\end{tabular}

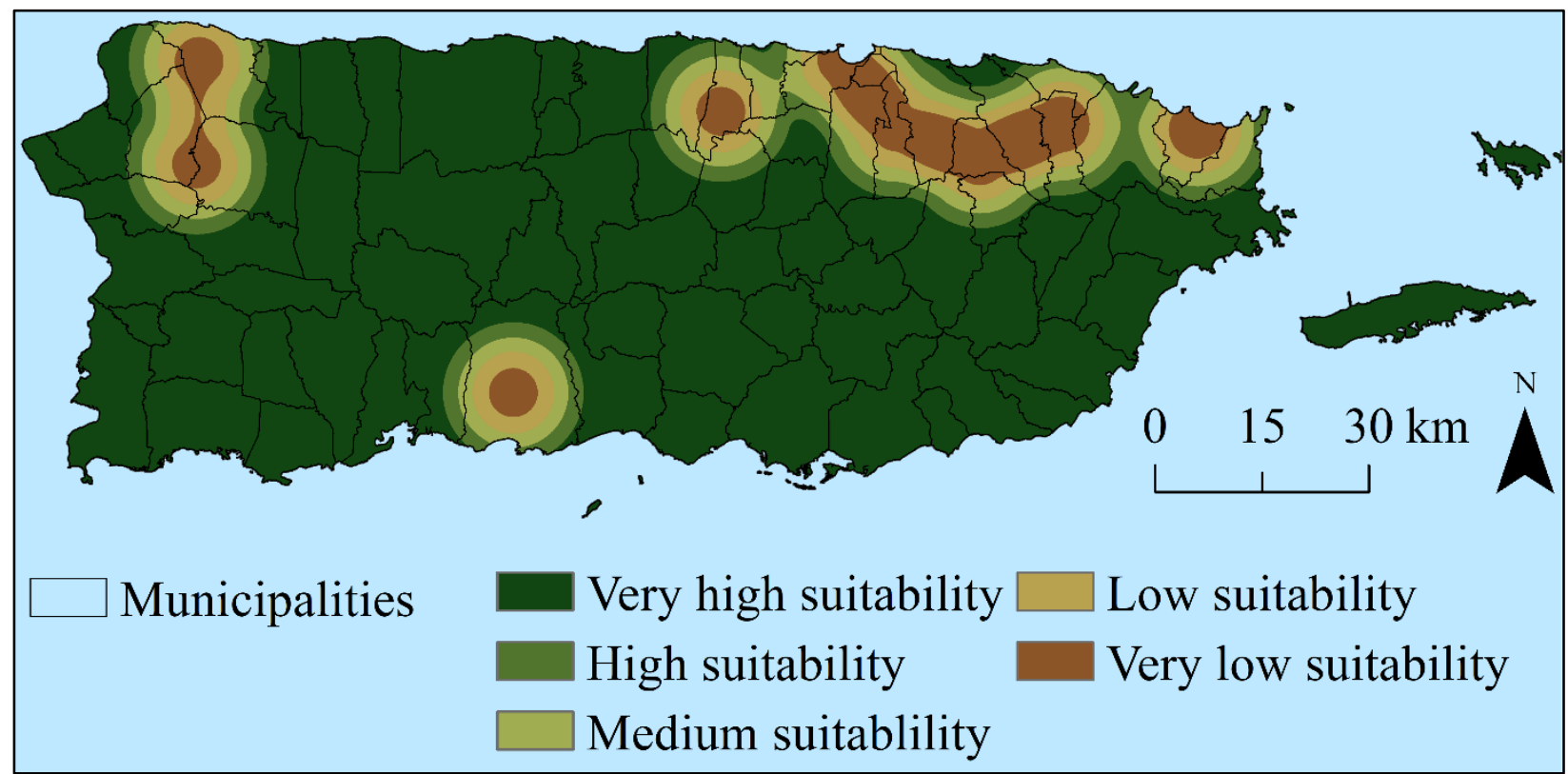

Figure 12: Suitability levels based on strong wind susceptibility.

\subsection{PHYSICAL CHARACTERISTICS}

The island of PR was also assessed for suitable sites to locate reserve generators based on the island's topography. Given the slope of a location, it could be susceptible to flooding events, which would make the site unsuitable for locating energy infrastructures. The purpose of assessing physical characteristics, specifically, slope, distance to coastline, and flood prone areas, was to exclude areas that may pose a risk to the functioning of reserve generators.

\subsubsection{Slope}

PR is a hilly island with highly undulating terrain and steep slopes. The central region of the island is most hilly with areas closer to the coastline relatively flat or gently slopped. Often the installation of a power generator or transformer involves transportation of heavy equipment to the site. It is therefore not 
desirable to locate these infrastructures on steep slopes because of challenges in transportation that could be time consuming and expensive, especially for mobile generators. Furthermore, steep slopes tend to be prone to landslides or earthflow during heavy precipitation and earthquakes. Flat to gently sloping terrain is therefore preferred to locate mobile energy infrastructures. The National Elevation Dataset (United States Geological Survey 2015) was used to generate a Digital Elevation Model from which slope for the entire island was calculated in degrees, and a set of thresholds (Table 6) were used to determine site suitability for locating reserve generators (Figure 13).

Table 6: Threshold criteria used to assign suitability levels - slope

\begin{tabular}{lcl}
\hline Value range (Degrees) & Class & Suitability level \\
\hline $0-5$ & 5 & Very High Suitability \\
$5-10$ & 4 & High Suitability \\
$10-15$ & 3 & Medium Suitability \\
$15-20$ & 2 & Low Suitability \\
$20-22.5$ & 1 & Very Low Suitability \\
$>22.5$ & 0 & Unsuitable \\
\hline
\end{tabular}

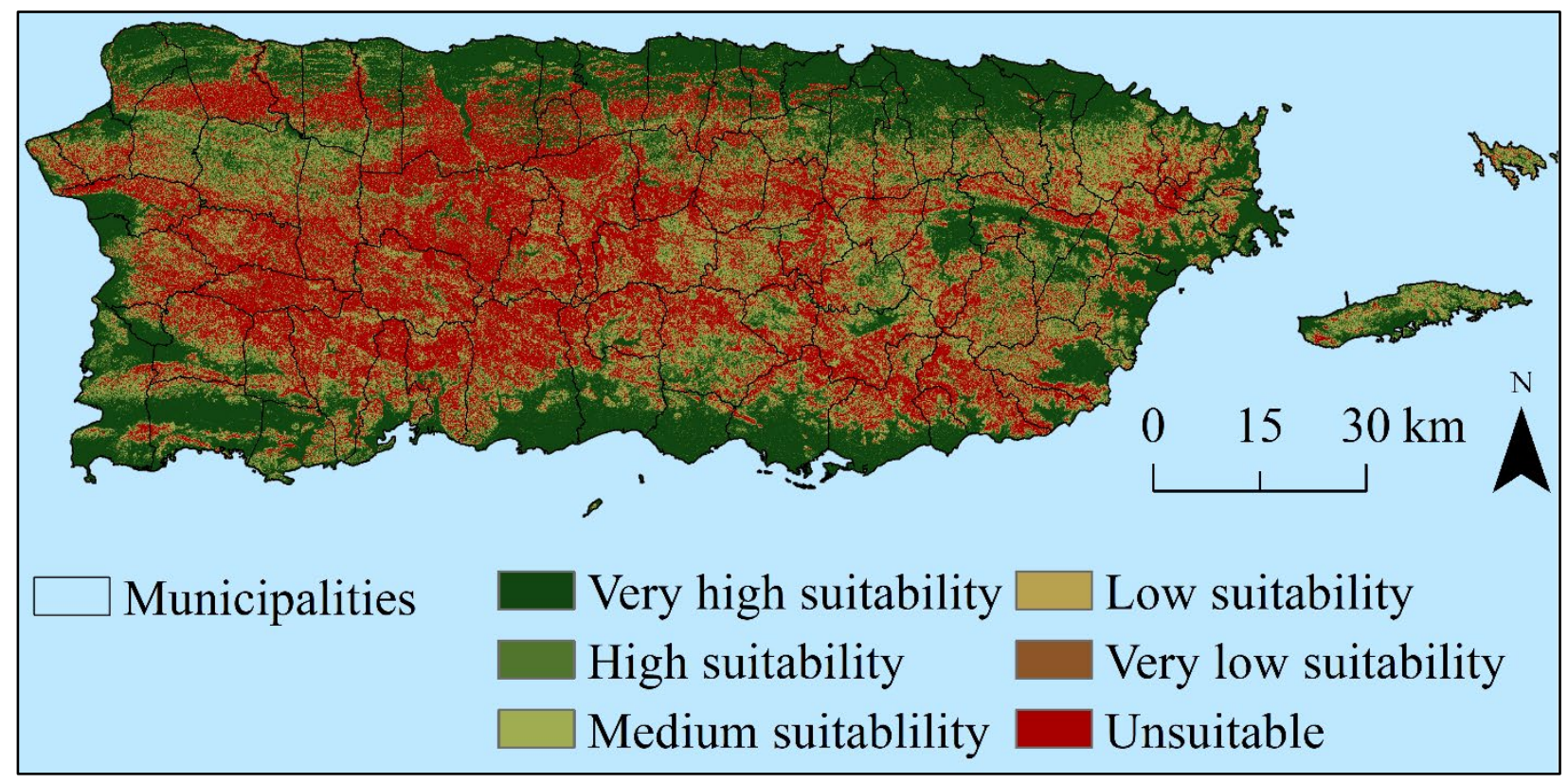

Figure 13: Suitability levels based on slope.

\subsubsection{Flooding}

While flat terrain is preferred to meet the goal of this study, it is crucial to ensure that the flat terrains are not prone to flooding as it would impact the functioning and maintenance of mobile energy infrastructures. Technically, low lying areas within flood plains are at high risk and should be avoided. To assess flood risk of potential sites, two approaches were implemented. First, the National Flood Hazard Layer (Federal Emergency Management Agency 2018) provided by the Federal Emergency Management Agency (FEMA) was used to identify flood plain areas. The data set contains information about flood risk areas designated as 100-year, 500-year, and 1000-year flood zones. A binary exclusion layer was created 
such that all areas beyond 100-year flood plains were considered suitable for siting, and all areas within the 100-year flood plain zones were considered as unsuitable (Figure 14).

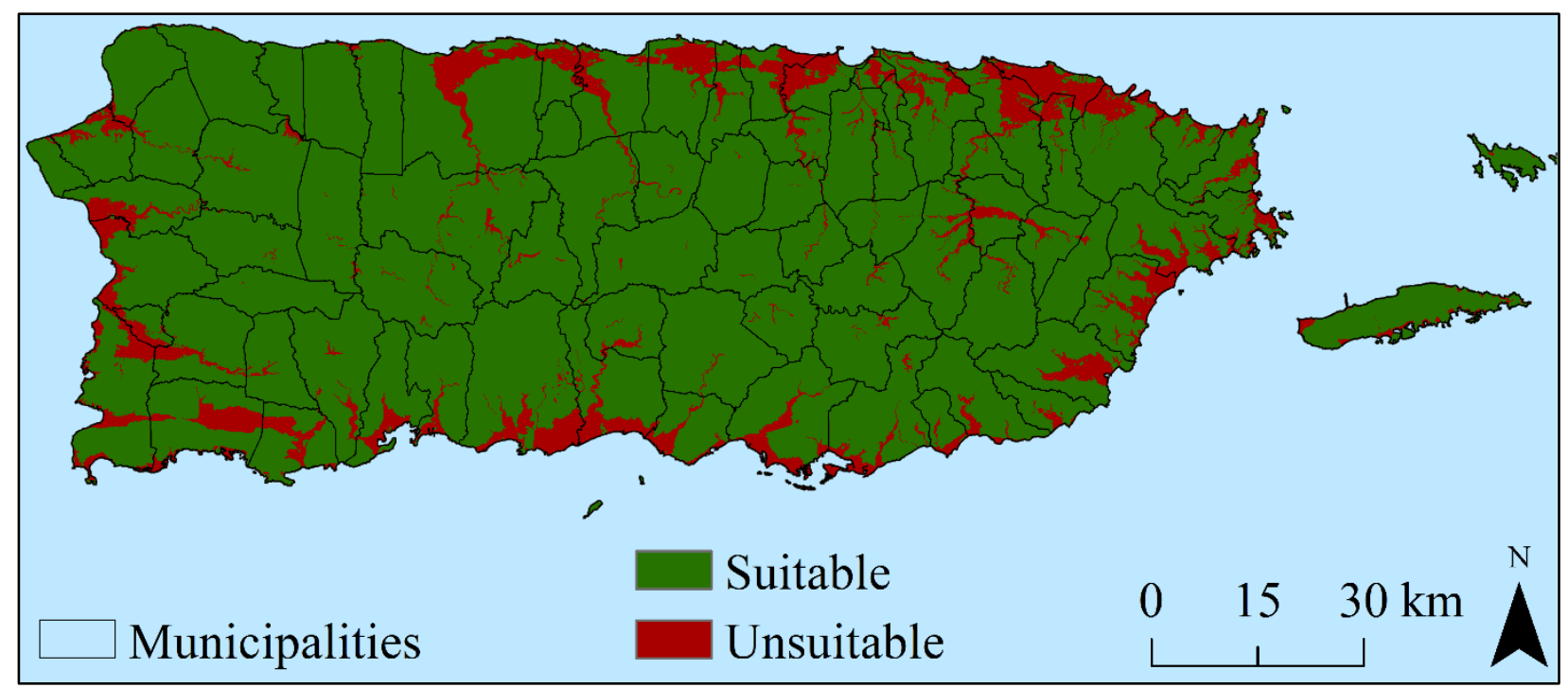

Figure 14: Suitability levels based on probability of flooding.

Second, the flood risk was evaluated using land cover information. The land cover data was obtained from the Multi-Resolution Land Characteristics Consortium's National Land Cover Database at approximately $30 \mathrm{~m}$ spatial resolution. This land cover data was derived from 2001 Landsat imagery. From this data, all areas identified as water or wetland were classified unsuitable because of flood risk. This resulted in another binary layer of suitable and unsuitable classes (Figure 15).

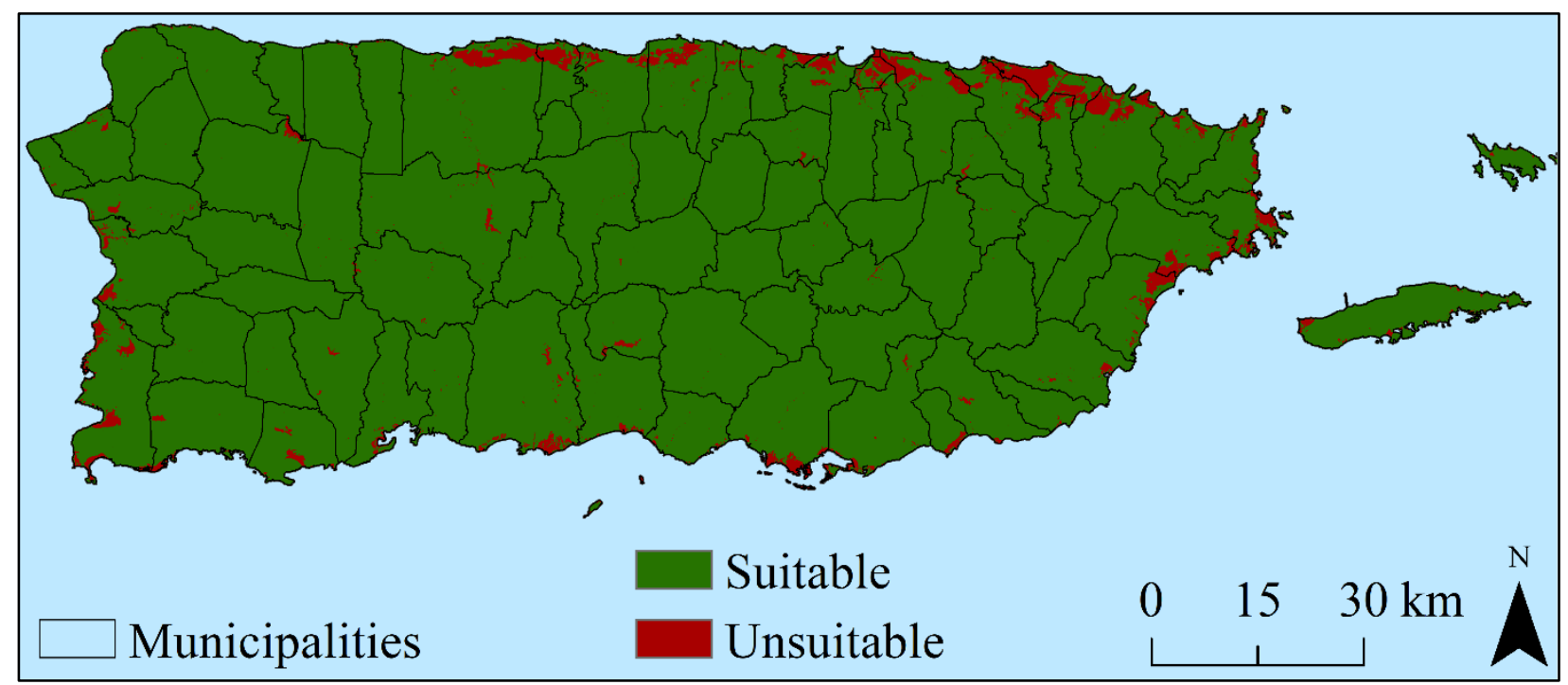

Figure 15: Suitability levels based on location within wetland zones.

\subsubsection{Storm Surge}

Storm surge is one of the most devastating extreme events that is caused by tropical storms, tsunamis, etc. A storm surge event results when the sea level changes due to changes in atmospheric pressure and wind associated with a storm. Storm surge events result in extensive flooding of coastal regions depending on the elevation of an area. Advances in atmospheric science have enabled prediction of expected storm 
surge levels given the probable strength of an extreme event and associated atmospheric conditions. The Sea, Lake, and Overland Surge from Hurricanes (SLOSH) model is one such fundamental modeling approach performed by the National Weather Service to estimate the height of a storm surge at a given location (Zachry et al. 2015). Through stochastic modeling, the SLOSH model produces worst-case coastal storm surge scenarios using the Maximum Envelops of Water model. NOAA has created the Maximum of the MEOWs (MOM) models which depicts the maximum and most conservative view of where coastal surge waters may reach. The output of the MOMs model was used in this project to determine the maximum inland extent of a storm surge during a worst-case scenario. Figure 16 shows the MOMs storm surge predictions for a category 5 hurricane.

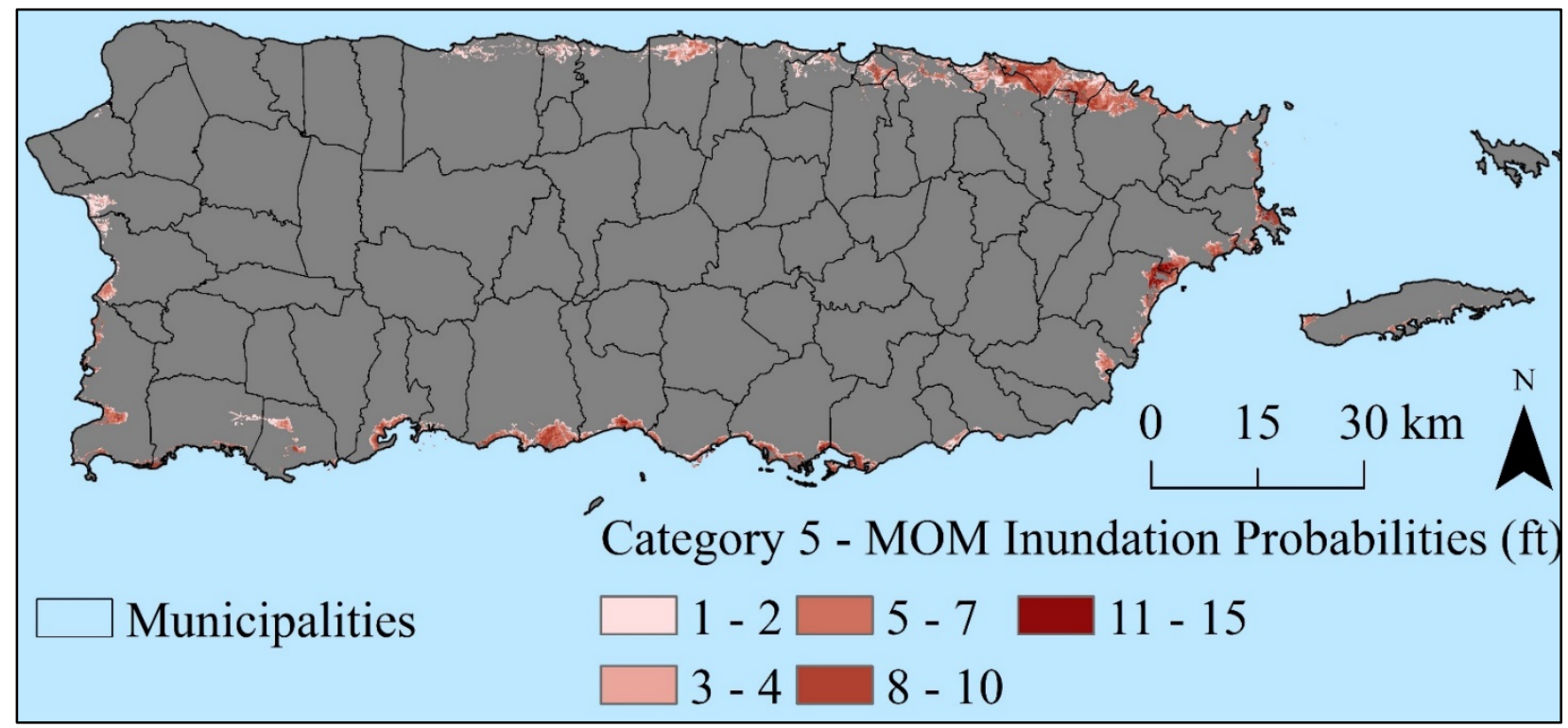

Figure 16: MOM storm surge probability levels.

Based on a worst-case scenario, 15 feet seems to be the maximum height above mean sea level that might be affected by a storm surge event. Using digital elevation data and 15 feet as the threshold, a binary layer was created (Figure 17). This layer depicts probable inundation zones, i.e., areas equal to or below 15 feet above mean sea level, which were classified as unsuitable for siting. The areas greater than 15 feet above mean sea level were classified as suitable for siting. 


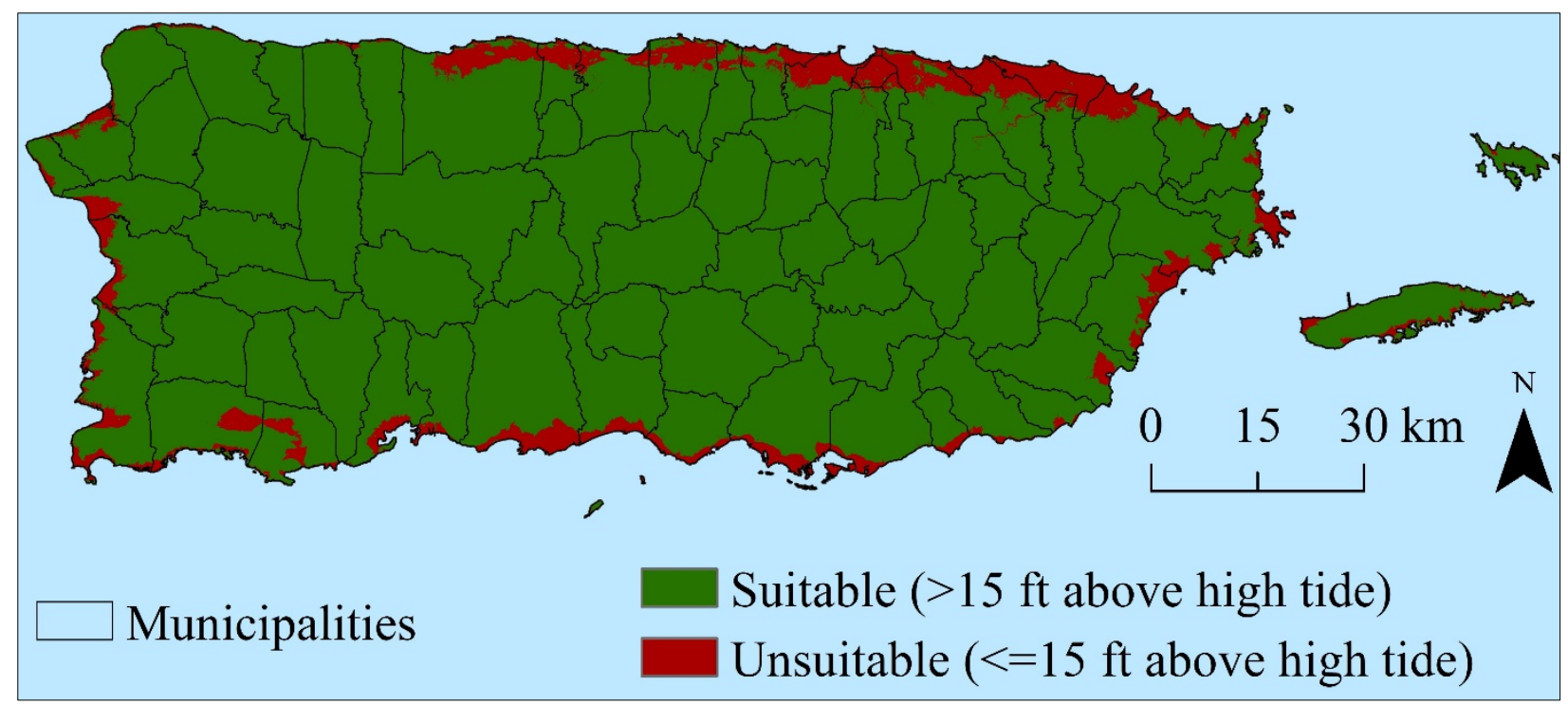

Figure 17: Suitability levels based on elevation of the coastal zone - storm surge risk.

There are areas along the coastline of the island that are less likely to be inundated, but they may not be accessible during a storm surge. An inland extent of two-miles was used to delineate an exclusion zone along the coastline. The inland areas within this exclusion zone have an elevation less than or equal to 15 feet above normal high tide. The inland areas beyond the exclusion zone were classified into five suitability levels at two-mile increments (Figure 18) such that the farthest inland areas were regarded as more suitable.

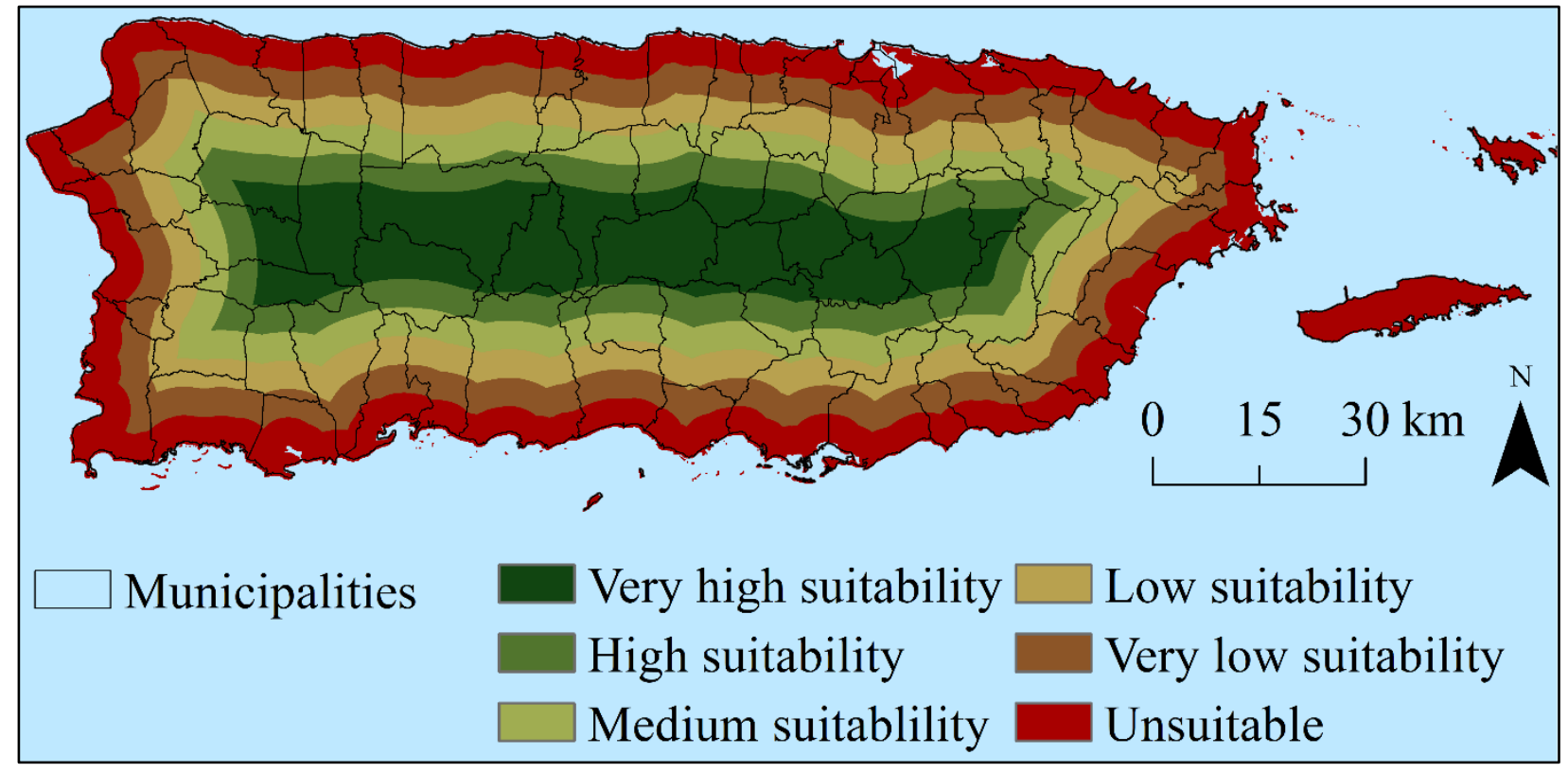

Figure 18: Suitability levels based on distance from the coastline - storm surge risk.

\subsection{PROTECTED LANDS}

Federal land including national parks, national monuments, national forests, wilderness areas, wild and scenic rivers, wildlife refuges, and American Indian reservations have specific regulations governing any form of use or development on site. In most cases, these lands have restricted use that excludes 
construction of any kind. These lands were therefore eliminated from being considered for siting generators. The workflow involved: (i) identifying federal protected lands, (ii) creating a raster layer for each protected land type (Table 1), (iii) merging raster layers to create a single layer of all protected lands, and (iv) creating the binary exclusion layer representing all protected lands as unsuitable (Figure 19).

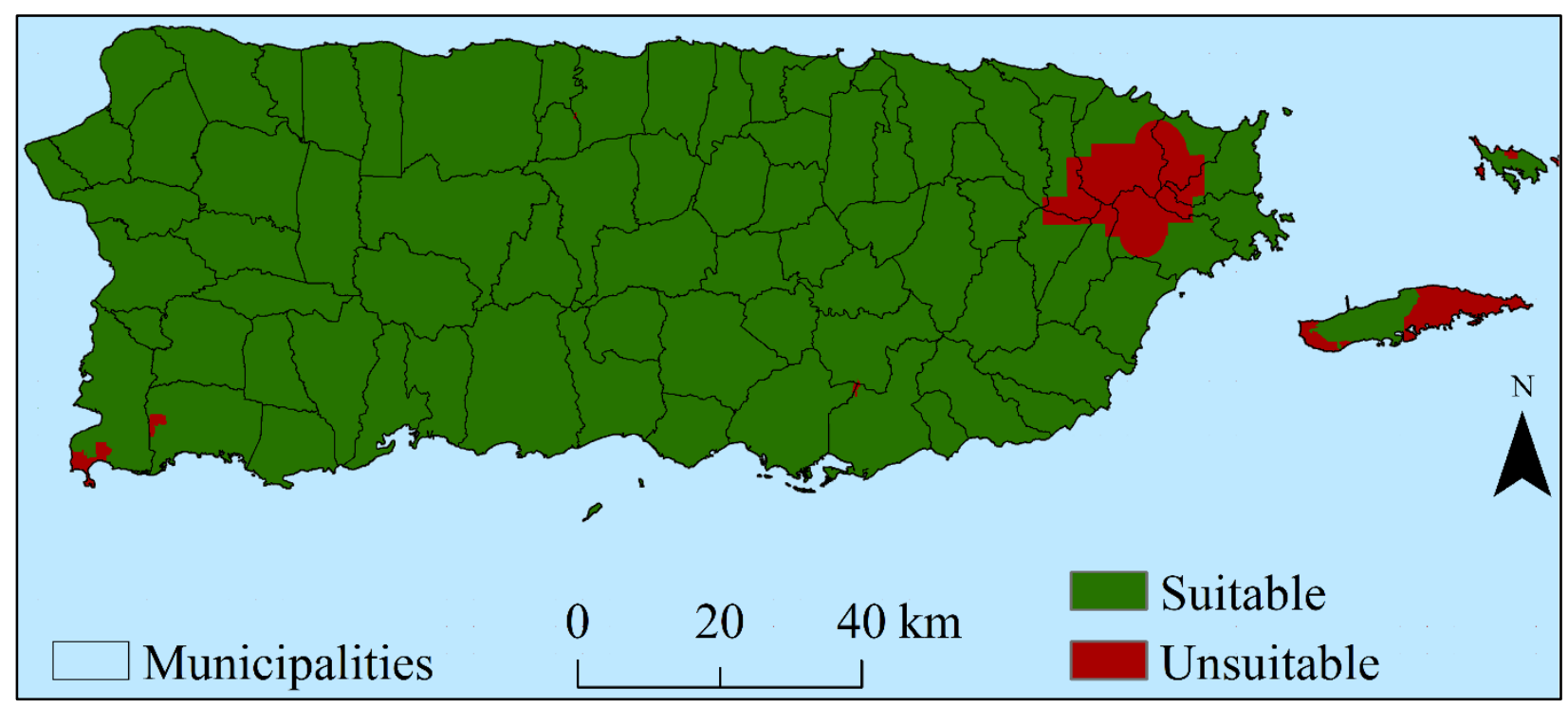

Figure 19: Suitability levels based on federal protected lands.

\subsection{SOCIO-ECONOMIC CHARACTERISTICS}

\subsubsection{Population Density}

The main purpose of this study was to identify locations for strategic placement of reserve generators such that during an extreme event these generators could serve maximum customers in need of power supply. Although guidelines recommend that power generators be located away from densely populated areas for safety purposes, rarely is any information provided about the health risks associated with a generator. For instance, nuclear reactors sites should be located in low density population areas such that a person standing at the boundary of the populated area will not receive a total radiation of 25 rem (i.e. Roentgen equivalent man) to the entire body or a total radiation of 300 rem to the thyroid from iodine exposure (United States Nuclear Regulatory Commision 2012). Other guidelines stipulate that areas within three miles of places inhabited by more than 2,500 people, and areas within one mile of places inhabited by less than 2,500 people should be avoided (Keeney 1980). Because this study focused on identifying sites for reserve generators and transformers, it is essential to locate this equipment near densely populated areas to ensure availability of electricity in the event of an extensive power outage. Using this criterion, exclusion zones were defined by absence of people within one-mile radius from any location.

LandScan data (Bright et al. 2017), a high-resolution population dataset representing ambient population distribution, was used to assess population density. The dataset is generated and was provided by the ORNL. The data is developed by combining census population counts with remote sensing data and using a dasymetric modeling approach to disaggregates census counts into spatial grids (Bhaduri et al. 2007). The LandScan population data was resampled from $\sim 90 \mathrm{~m}$ spatial resolution to $30 \mathrm{~m}$ spatial resolution to match the rest of the data layers. Using the resampled raster layer, a focal sum was performed to determine total population within a one-mile radius of each grid cell. From the resulting layer, all grid cells with a value of zero were classified as unsuitable, and remaining grid cells were classified into five 
suitability levels according to the criteria in Table 7, giving more preference to areas with higher population concentration (Figure 20).

Table 7: Threshold criteria used to assign suitability levels - Population

\begin{tabular}{lcl}
\hline Value range (Degrees) & Class & Suitability level \\
\hline $30,000-483,466$ & 5 & Very High Suitability \\
$15,000-30,000$ & 4 & High Suitability \\
$5,000-15,000$ & 3 & Medium Suitability \\
$2,000-5,000$ & 2 & Low Suitability \\
$1-2,000$ & 1 & Very Low Suitability \\
0 & 0 & Unsuitable \\
\hline
\end{tabular}

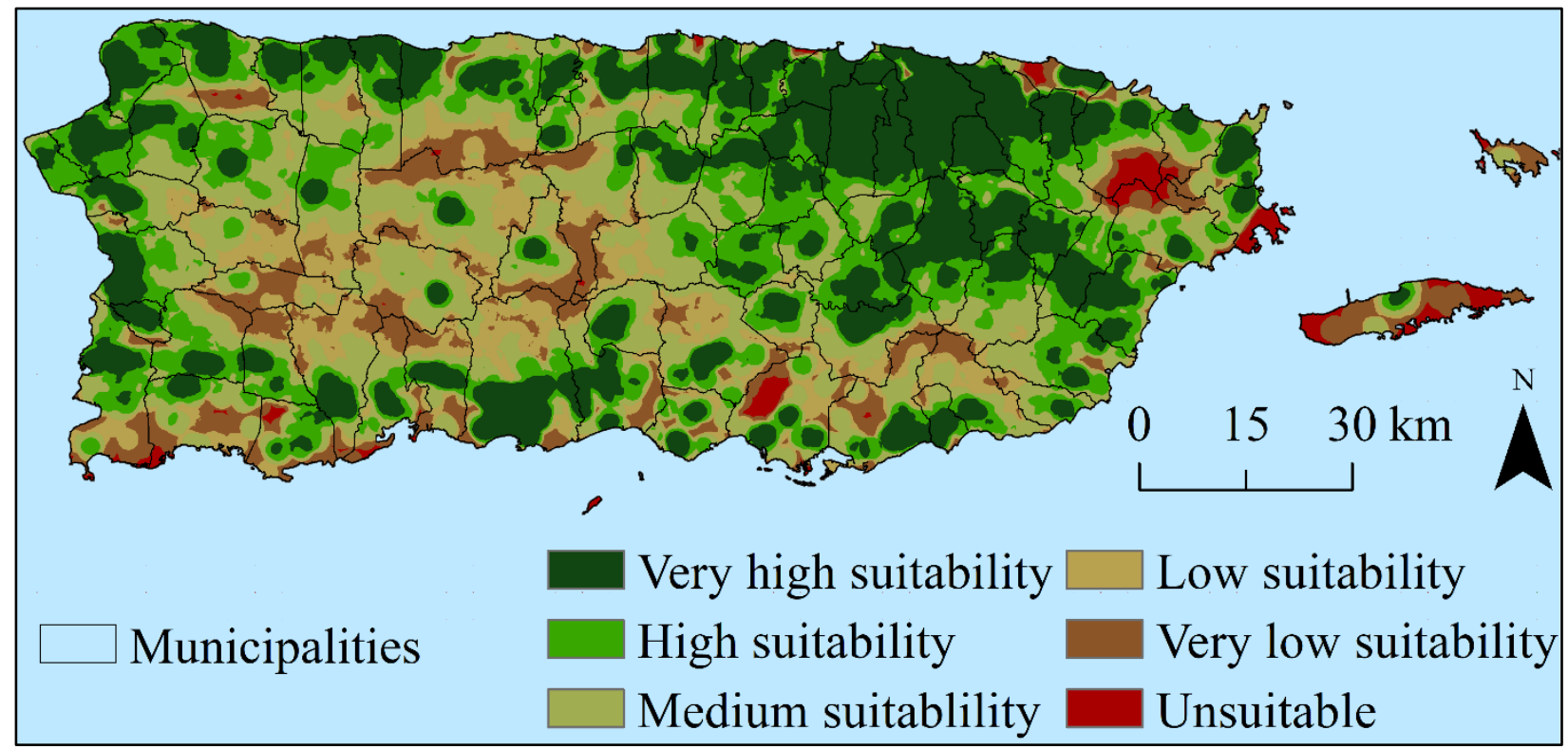

Figure 20: Suitability levels based on population density.

\subsection{TRANSPORTATION}

The equipment needed for storing energy (i.e., reserve generators and transformers) could be transported by ocean vessel, barge, railroad, heavy duty trailer transport, or heavy-haul transporter. The selected mode will depend on the weight, size, and shape of equipment as well as the availability of transportation modes. In most cases, multiple modes may be used if direct access to a single mode is not possible. In this study, probable siting locations were analyzed by considering all feasible transportation options to the assembly site, and in case of mobile transformers and reactors, from the site to disaster affected areas.

Ideally, a selected site should be accessible through multiple modes of transportation in case one or the other is damaged during the catastrophic event. Within PR, the major mode of transportation is road followed by railroad in the city of San Juan. Site suitability based on transportation was determined by considering accessibility by road or rail to potential suitable sites. The following criteria were used to evaluate transportation routes (Institute of Electrical and Electronic Engineers 2012).

i. Dimension clearance - The roads should be wide enough to allow transportation of oversized equipment. 
ii. Maximum allowable axle load: In case of bridges, overpasses, and tunnels, it is essential to determine the load that could be carried so that if needed, existing bridges could be reinforced or retrofitted, or temporary ones could be built. Given that some roads have a limited allowable axle load during bad weather, it is essential to identify these roads.

iii. Identify solid/all-weather roads, and roads needing paving, matting or steel plates.

iv. Re-grade roads if necessary to reduce incline e.g., on intersections, rail crossings, and site entrances.

v. Identify utility services, such as cable lines, telephone and power lines along road networks that would be impacted by transporting heavy equipment.

vi. Finally, determine private properties that would require permission for transportation.

Although these criteria are crucial, the detailed data needed for such level of evaluation are unavailable for PR. However, road network centerlines were available for the island. The widths of the roads were adjusted according to specifications (Table 8) given by the Federal highway administration (American Association of Sate Highways and Transportation Officials 2005).

Table 8: Road width specifications

\begin{tabular}{lcl}
\hline Type of roadway & US (feet) & Metric (meters) \\
\hline Freeway & 12 & 3.6 \\
Ramps (1-lane) & $12-30$ & $3.6-9.2$ \\
Arterial & $10-12$ & $3.3-3.6$ \\
Collector & $10-12$ & $3.0-3.6$ \\
Local & $9-12$ & $2.7-3.6$ \\
\hline
\end{tabular}

Essentially, interstates are designated for a minimum of four traffic lanes each at least 12 feet wide and a paved shoulder of 10 feet minimum width on the right side, and four feet on the left side. For sections of interstates with six or more lanes, a minimum of 10 feet wide left shoulders is provided. A range in lane widths from nine feet to 12 feet, in shoulder widths from 2 feet to six feet, and in total width from 22 feet to 36 feet for local roads is recommended. Buffers were created on the road and street centerlines using the criteria identified in Tables 8 and 9 to create the maximum road width needed to transport energy infrastructures.

Table 9: General road width adjustments used for current application

\begin{tabular}{llcccc}
\hline Type of roadway & $\begin{array}{l}\text { US (ft) } \\
\text { per lane }\end{array}$ & \# Lanes & $\begin{array}{c}\text { Right } \\
\text { shoulder (ft) }\end{array}$ & $\begin{array}{c}\text { Left } \\
\text { Shoulder (ft) }\end{array}$ & $\begin{array}{c}\text { Total } \\
\text { Width (ft) }\end{array}$ \\
\hline Freeway/Interstate & 12 & 4 & 10 & 4 & 62 \\
Secondary/ Major roads & $10-12(11)$ & 4 & 6 & 2 & 52 \\
Primary / Local & $9-12(10)$ & 2 & 6 & 2 & 28 \\
Ramps (1-lane) & $12-30(12)$ & 1 & & & 12 \\
\hline
\end{tabular}

Because not all roads were clearly classified, a uniform width of 62 feet (Table 9) was applied for each divided highway of the interstates or freeway. Major roads, secondary roads, and local connecting roads were assumed to be undivided and have an average of four lanes, each 12 feet wide. For these roads, a uniform width of 52 feet was applied including a six feet wide right shoulder, and one two feet wide left shoulder. Local roads were assumed to have two lanes. A total width of 28 feet was applied to these roads that included two 10 feet wide lanes, one six feet wide right shoulder and one two feet left shoulder. All roads classified as primary and above were considered as appropriate for heavy haul transportation. Site suitability was assessed based on accessibility by a qualified road. Accessible sites were defined as those 
within $100 \mathrm{~m}$ of primary or higher road. Figure 21 shows the transportation network in PR including interstates, secondary and primary roads, ramps and railroad.

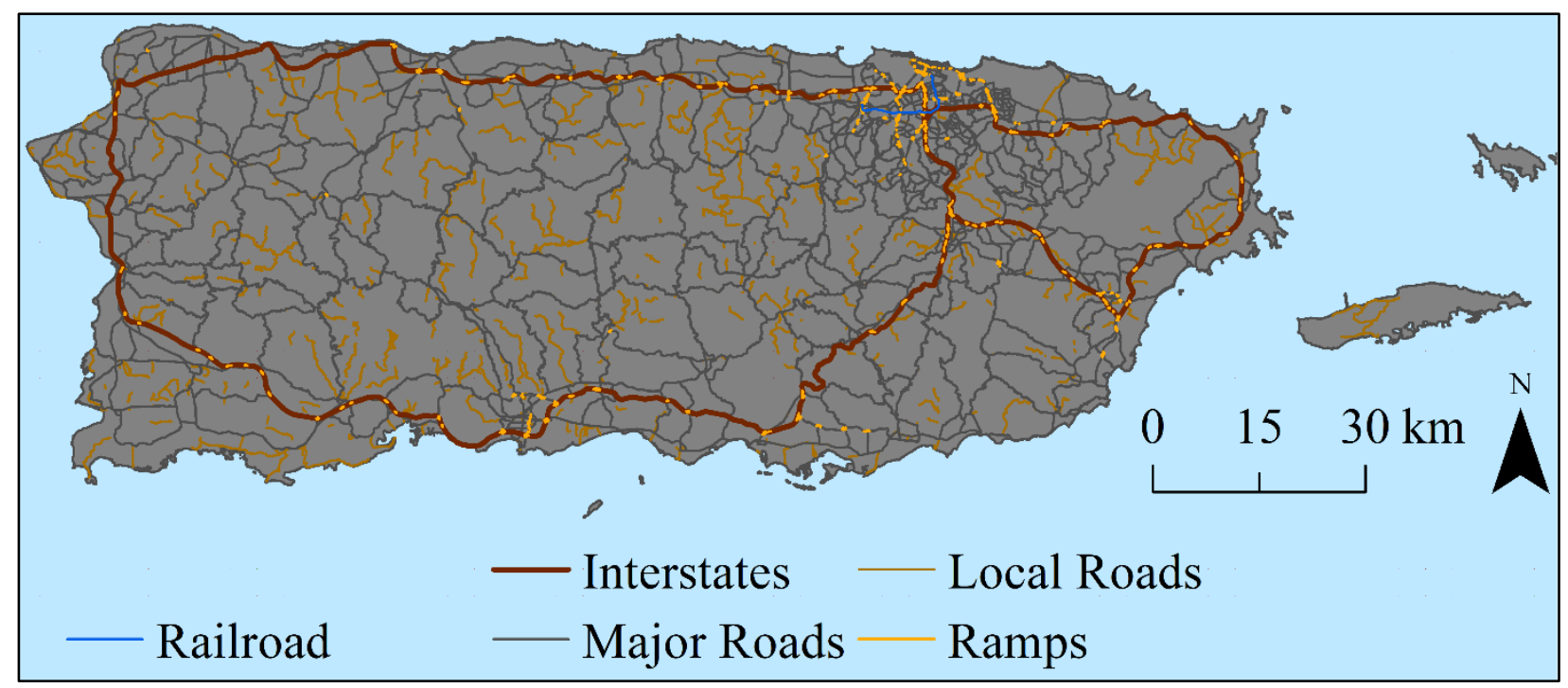

Figure 21: Centerline road network in PR.

Figure 22 shows the width adjusted road network with an inset portion illustrating the accessibility extent defined by $100 \mathrm{~m}$ buffer distance.

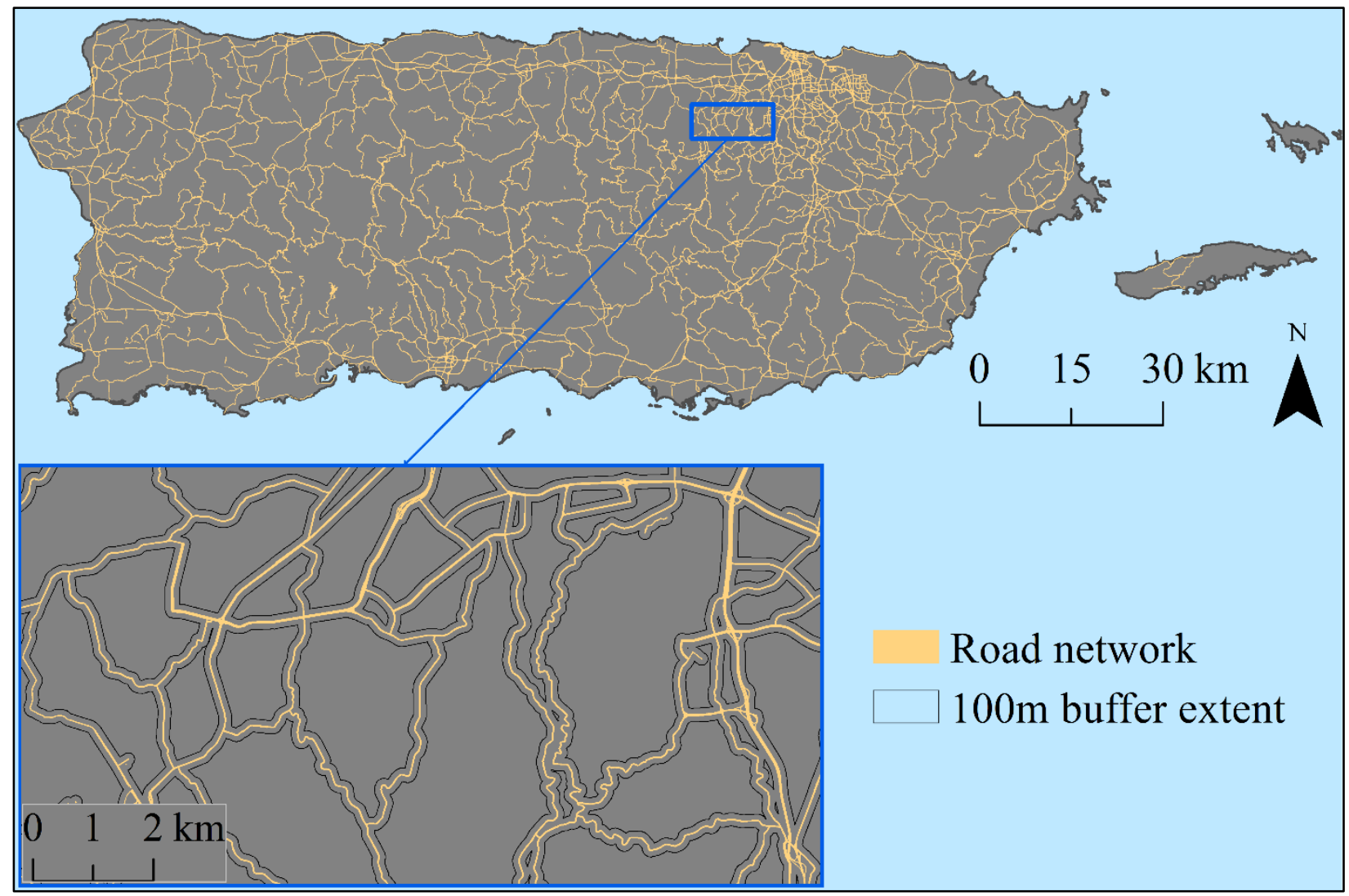

Figure 22: Width adjusted road network and accessibility buffer distance. 
The standard width of rail (distance between the rails) in the United States is 4 feet, 8.5 inches. A loading gauge defines the maximum height and width for railway vehicles and their loads to ensure safe passage through bridges, tunnels and other structures. In North America, the standard loading gauge is about 10 feet 8 inches wide and 15 feet 2 inches tall to $20 \mathrm{ft} 2 \mathrm{in}$ tall for double stacked containers. The width of the rail line was adjusted to 10 feet 8 inches. Figure 23 shows the extent of the railroad with nearby connecting road network.

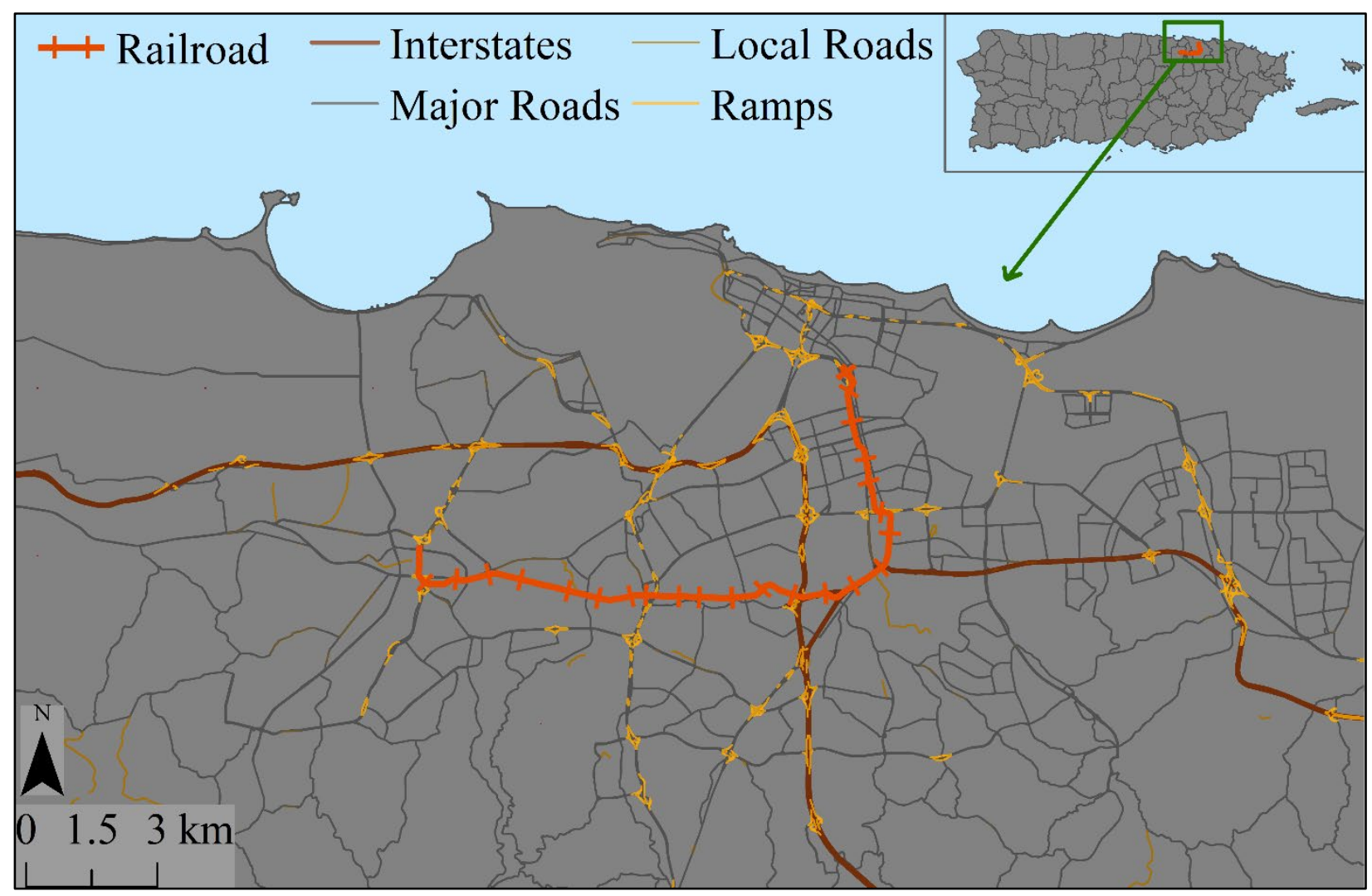

Figure 23: Width adjusted rail road and nearby connecting road network.

\subsection{POTENTIAL FACILITIES}

Although alternate sites could be identified using the approach discussed herein to locate energy equipment, it is prudent to have equipment housed in existing facilities, such as colleges and universities, prisons, hospitals, and military bases. These facilities often serve as refuges in the event of emergencies such as during hurricane Maria. Furthermore, they also provide critical services, such as treatment centers for sick and injured population, maintaining security during emergency events. Locating the reserve generators in these facilities would therefore allow easy access to power supply to many impacted populations. It is also assumed that these facilities have sound structures that would protect the reserve generators during extreme events and other emergencies. All of the facility layers were combined to create one raster layer of potential facilities at $30 \mathrm{~m} \times 30 \mathrm{~m}$ spatial resolution (Figure 24). Further analysis was performed to establish overall suitability of the sites based on computed suitability of the current technique. This assessment is presented in the results section of the report. 


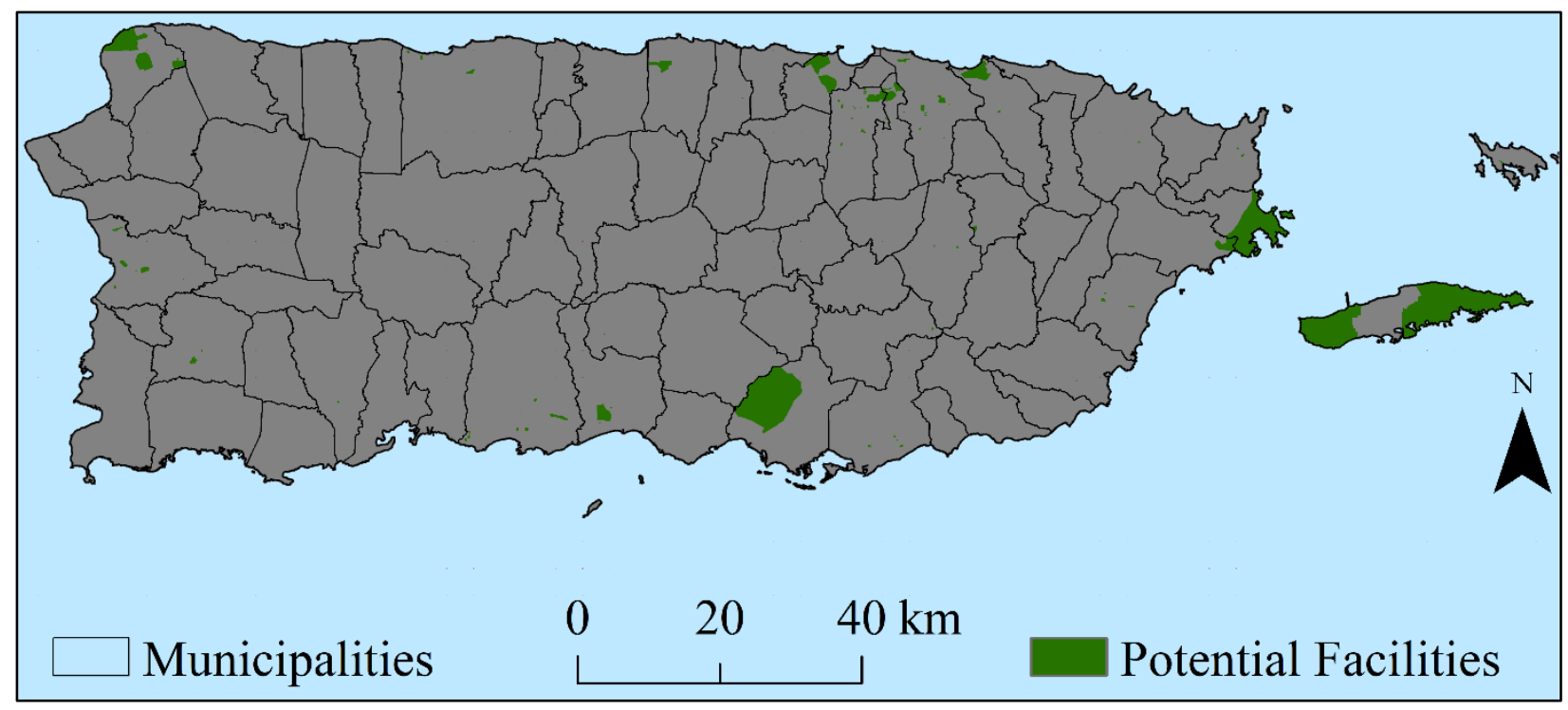

Figure 24: Potential existing siting facilities.

\section{RESULTS}

\subsection{THE BASE LAYER}

The base layer provides information on total suitability scores at each $30 \mathrm{~m} \times 30 \mathrm{~m}$ grid cell based on all of the ranked layers (Figure 25). Higher scores in the base layer indicate more suitable locations for siting reserve generators. Total score values were scaled into five classes using the Jenks natural breaks algorithm such that similar values were grouped together while maximizing the differences between the classes. This classification algorithm (Smith, Goodchild, and Longley 2006) places class boundaries where data values relatively differ. The method was applied as implemented in the Esri ArcMap version 10.4 software to obtain the base layer in Figure 26.

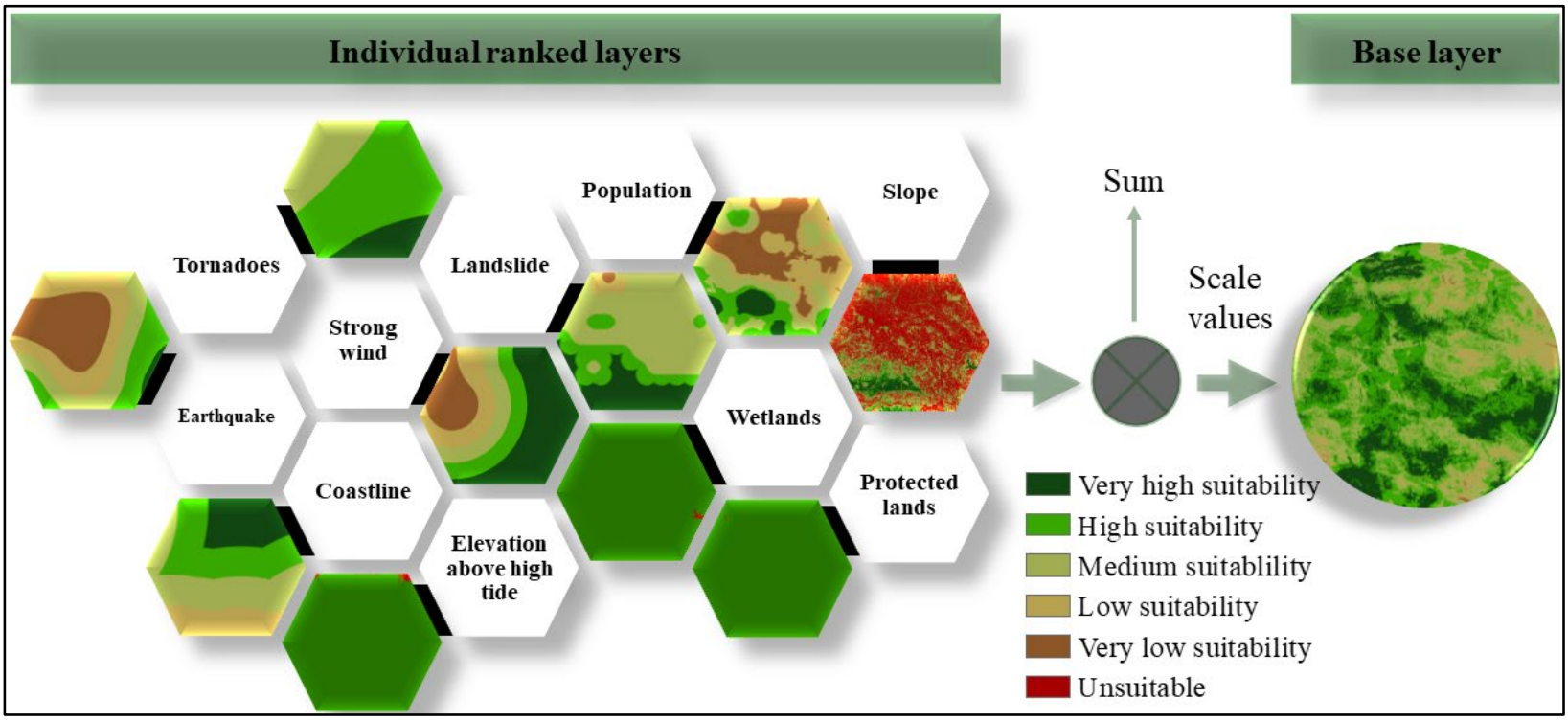

Figure 25: Base layer implementation method. 


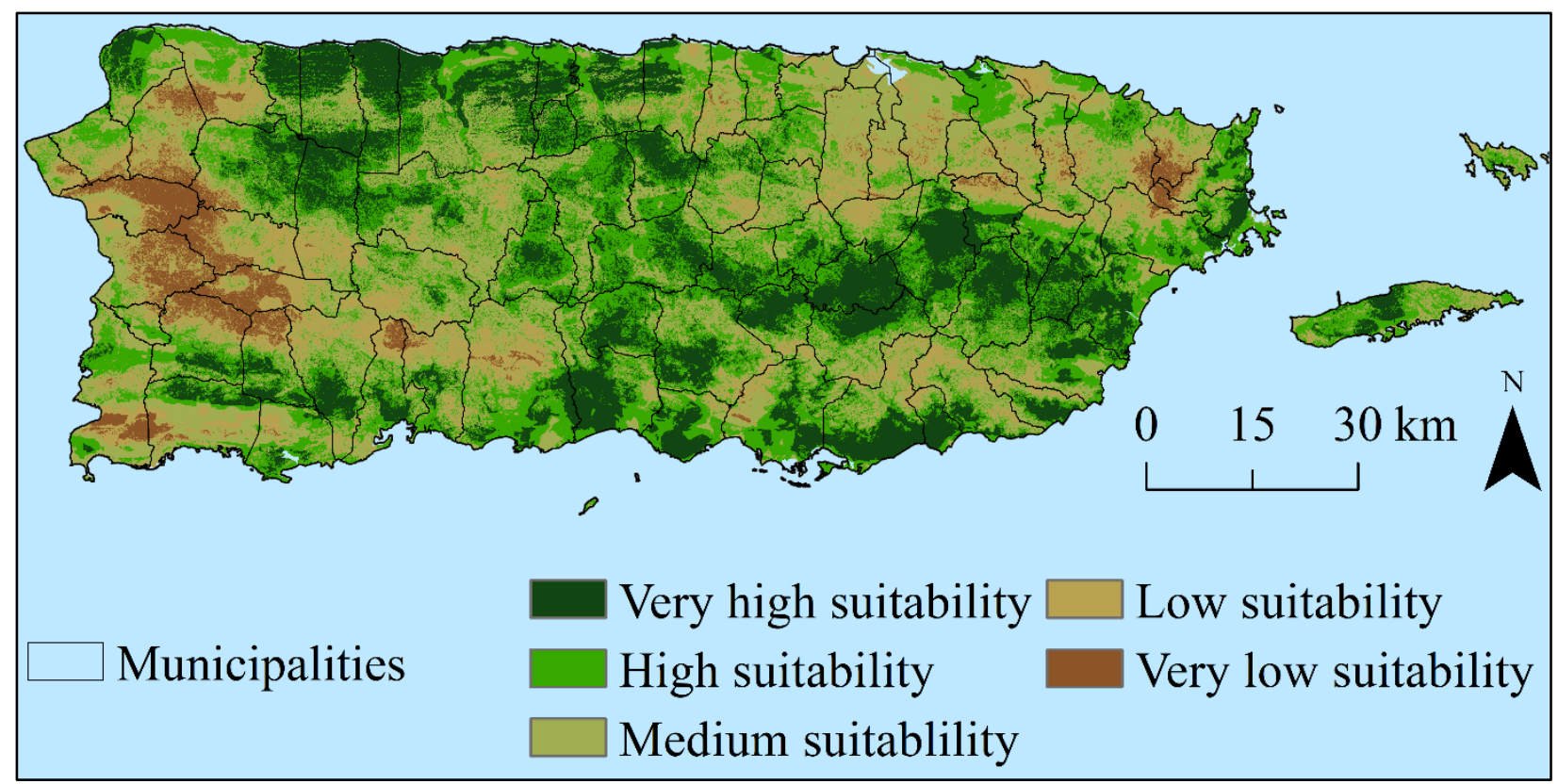

Figure 26: Base Layer.

\subsection{EXCLUSIONARY CRITERIA}

Exclusionary criteria were developed so that locations meeting the set criteria are excluded from consideration as potential placement sites. These criteria ensured each factor considered for site evaluation met set guidelines, and potential siting constraints were avoided or minimized. While the base layer provides overall rating of sites based on all the factors, the exclusion layer identified unsuitable sites that failed to meet the criteria for suitability based on many factors or presented conflict for placement of energy infrastructures as intended by this study. For example, sites at high risk of being impacted by natural hazards or those experiencing challenges related to mobility or policies restricting their use were excluded from being considered. Table 10 outlines the exclusion criteria used to define undesirable sites. Figure 27 depicts the spatial distribution of suitable and unsuitable sites based on these exclusion criteria. 
Table 10: Exclusionary criteria used to define unsuitable sites

\begin{tabular}{|c|c|c|c|}
\hline Category & Consideration & Measure & Exclusion criteria \\
\hline $\begin{array}{l}\text { Natural } \\
\text { disasters }\end{array}$ & Landslides & $\begin{array}{l}\text { Probability of landslide } \\
\text { occurrence }\end{array}$ & $\begin{array}{l}\text { Areas with }>25 \text { recorded landslides } \\
\text { per square kilometer }\end{array}$ \\
\hline \multirow[t]{5}{*}{$\begin{array}{l}\text { Physical } \\
\text { Characteristics }\end{array}$} & \multirow[t]{2}{*}{ Storm surge } & $\begin{array}{l}\text { Elevation above normal } \\
\text { high tide level }\end{array}$ & $\begin{array}{l}\text { Areas along the coastline that are } \\
<=15 \mathrm{ft} \text { below normal high tide. }\end{array}$ \\
\hline & & $\begin{array}{l}\text { Euclidean distance from } \\
\text { the coastline }\end{array}$ & $\begin{array}{l}\text { Areas within two miles of the } \\
\text { coastline }\end{array}$ \\
\hline & \multirow[t]{2}{*}{ Flooding } & Location within wetlands & $\begin{array}{l}\text { All areas classified as wetlands or } \\
\text { open water }\end{array}$ \\
\hline & & Probability of flooding & $\begin{array}{l}\text { All areas with the } 100 \text {-year flood } \\
\text { hazard zone }\end{array}$ \\
\hline & $\begin{array}{l}\text { Potential earth } \\
\text { failure, } \\
\text { mobility and } \\
\text { development } \\
\text { challenges }\end{array}$ & $\begin{array}{l}\text { Topographic slope } \\
\text { (Degree of steepness) }\end{array}$ & $\begin{array}{l}\text { All areas greater than } 22.5 \text { degrees are } \\
\text { excluded }\end{array}$ \\
\hline Protected lands & $\begin{array}{l}\text { Land use } \\
\text { restrictions }\end{array}$ & $\begin{array}{l}\text { Location within protected } \\
\text { lands }\end{array}$ & $\begin{array}{l}\text { Areas inside of designated protected } \\
\text { or ecological lands }\end{array}$ \\
\hline $\begin{array}{l}\text { Socio-economic } \\
\text { characteristics }\end{array}$ & $\begin{array}{l}\text { Population } \\
\text { density }\end{array}$ & $\begin{array}{l}\text { Number of persons } \\
\text { within a mile radius }\end{array}$ & $\begin{array}{l}\text { Areas with } 0 \text { persons within a mile } \\
\text { radius }\end{array}$ \\
\hline
\end{tabular}




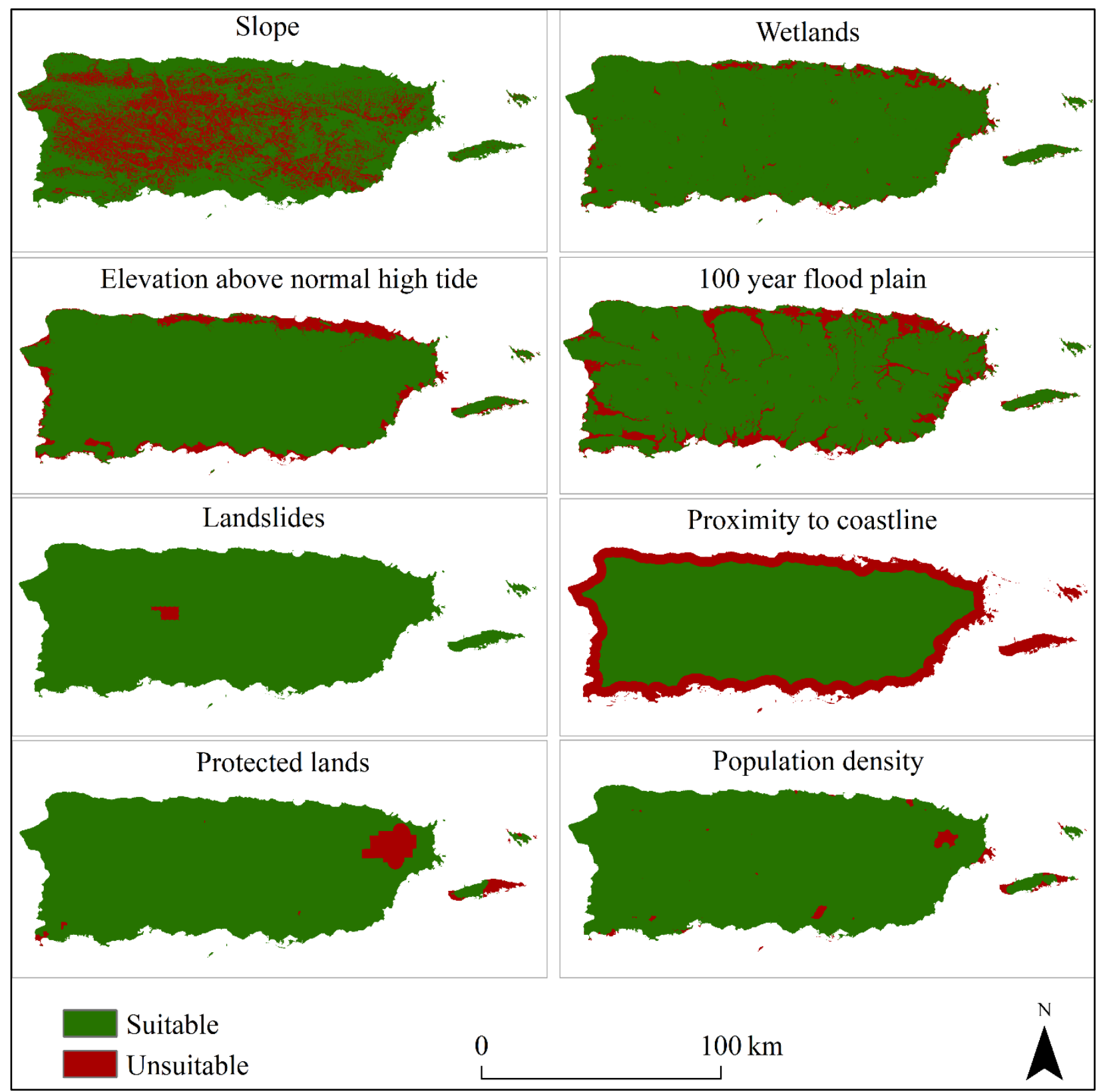

Figure 27: Individual exclusion layers

Suitable areas in each exclusion layer were assigned a value of 1 and unsuitable areas were assigned a value of 0 . Aggregation of exclusion layers through multiplication produced a single exclusion layer (Figure 28) indicating suitable areas (value of 1), and unsuitable areas (value of 0). The suitable areas display unranked sites that have the potential for locating reserve generators. This final layer was multiplied with the base layer to generate the final suitability layer that ranked sites based on their suitability score into five classes. 


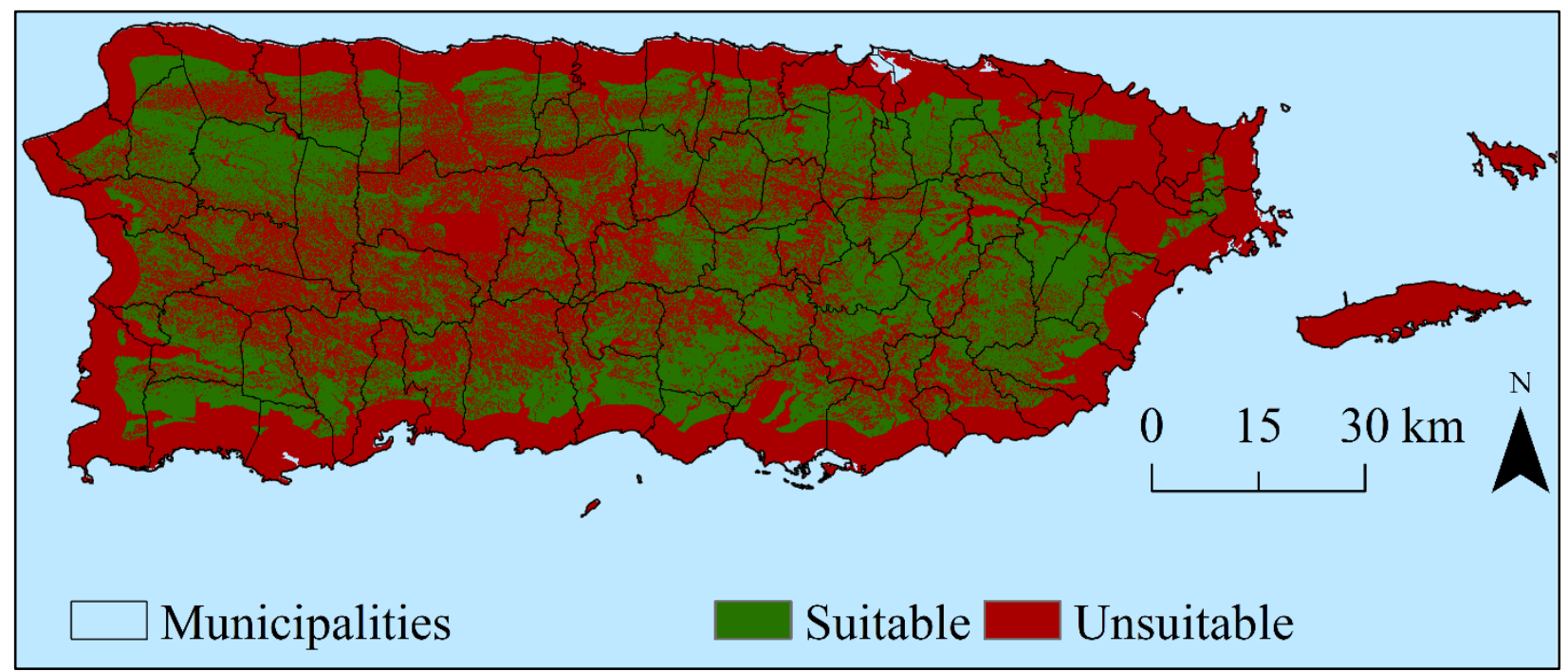

Figure 28: Exclusion layer.

\subsection{SITE SUITABILITY}

Figure 29 displays the potential placement sites based on their suitability scores. More than half (55.9\%) of the PR land area was found to be unsuitable for siting generator reserves. This leaves us with about $45 \%$ of the land area of which about $14 \%$ was found to very highly suitable, $15 \%$ as highly suitable, $10 \%$ as moderately suitable, $3.3 \%$ with low suitability and $0.8 \%$ with very low suitability. The suitable areas are located 2-miles inland along the outer edges of the island. Most of the unsuitable sites are located around the protected forest region to the east of the island. Most of the highly suitable sites are located along the eastern and north-western, and southern part of the island. Sites surrounding the city of San Juan were found to have medium to low suitability mostly because of their presence in hazardous places prone to tornadoes, strong winds, and earthquakes. Although the outer edges of the island have high population concentration, the suitable sites are not located close to these places. Hence, site selection would require considering highly suitable sites that are near populated areas.

Table 11:Percent land area under different suitability levels

\begin{tabular}{ll}
\hline Suitability level & Percent land urea \\
\hline Very High Suitability & 14.32326 \\
High Suitability & 15.41936 \\
Medium Suitability & 10.34533 \\
Low Suitability & 3.308406 \\
Very Low Suitability & 0.75062 \\
Unsuitable & 55.85303 \\
\hline
\end{tabular}




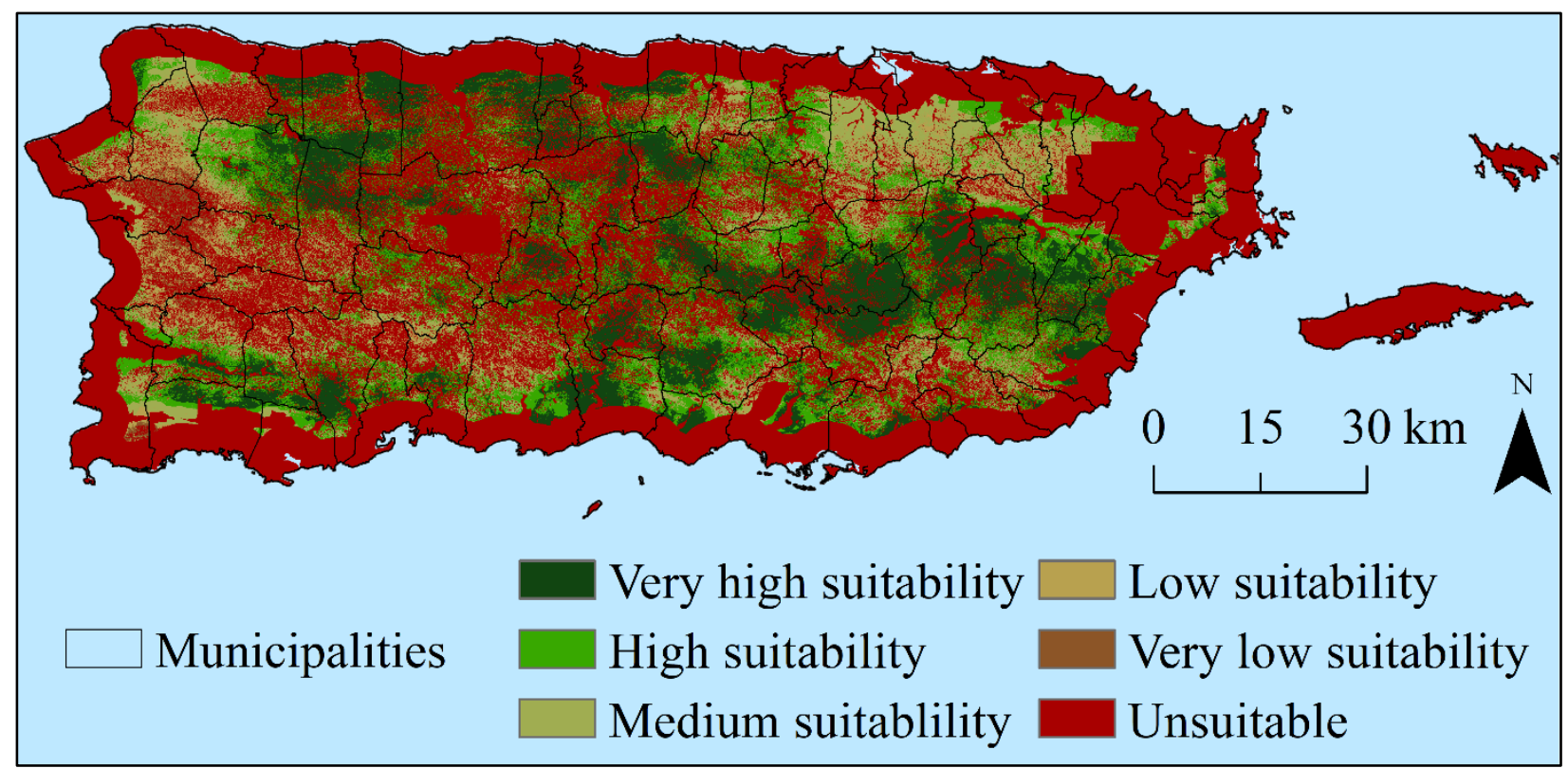

Figure 29: Site suitability levels.

\subsection{SITE ACCESSIBILITY}

Although suitable sites are needed for locating equipment for redundant power supply in case of extreme events, these sites must be accessible by roads to ensure transportation of equipment from different places in the island. In this study, all sites that are within 100 meters of a primary or major road were considered highly suitable due to their proximity to roads, given the cost of establishing a new road is significantly high. While Figure 30 shows the road networks in the island, Figure 31 displays the suitable sites that are accessible by major roads.

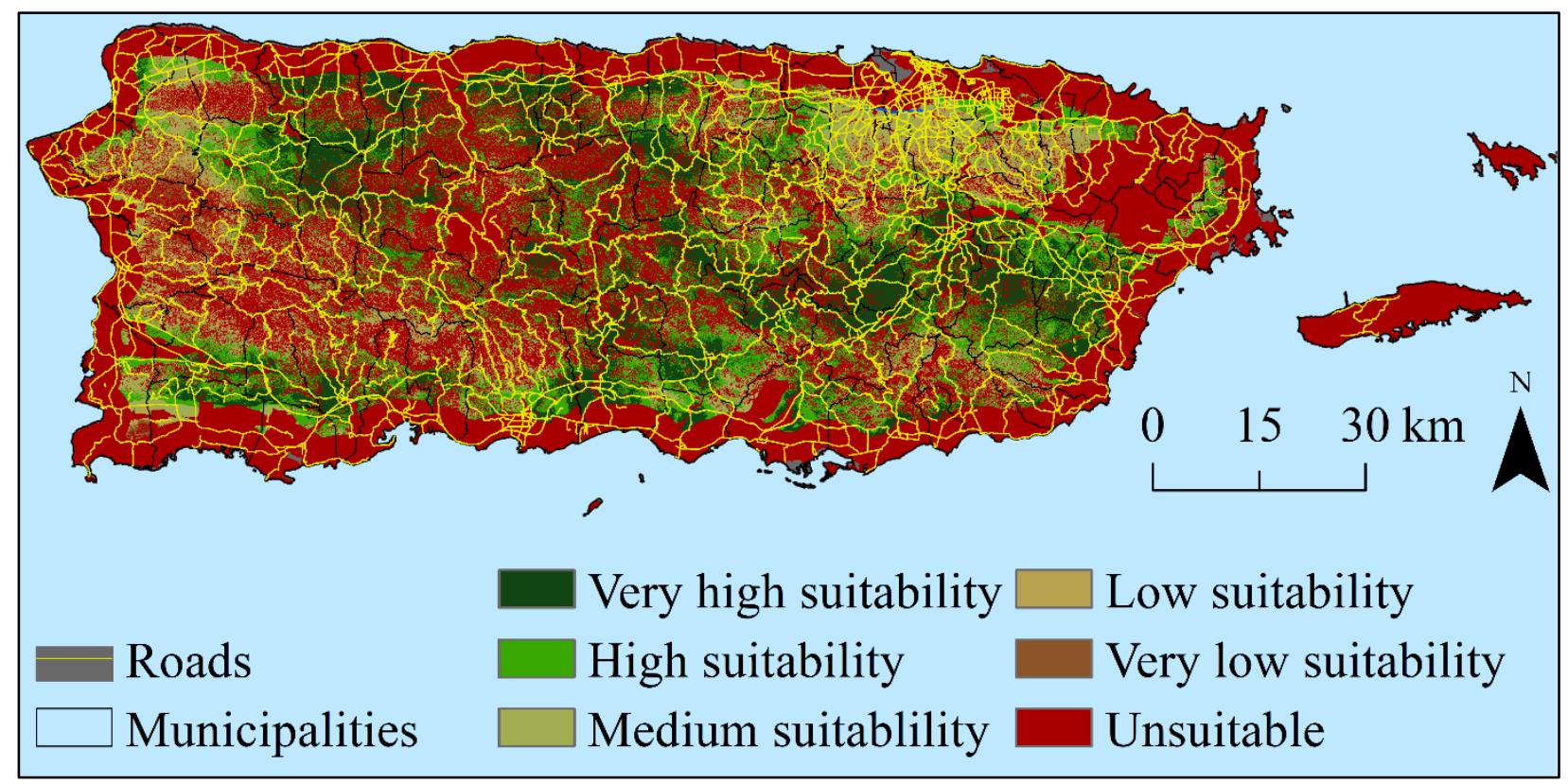

Figure 30: Road accessibility of various suitability categories. 


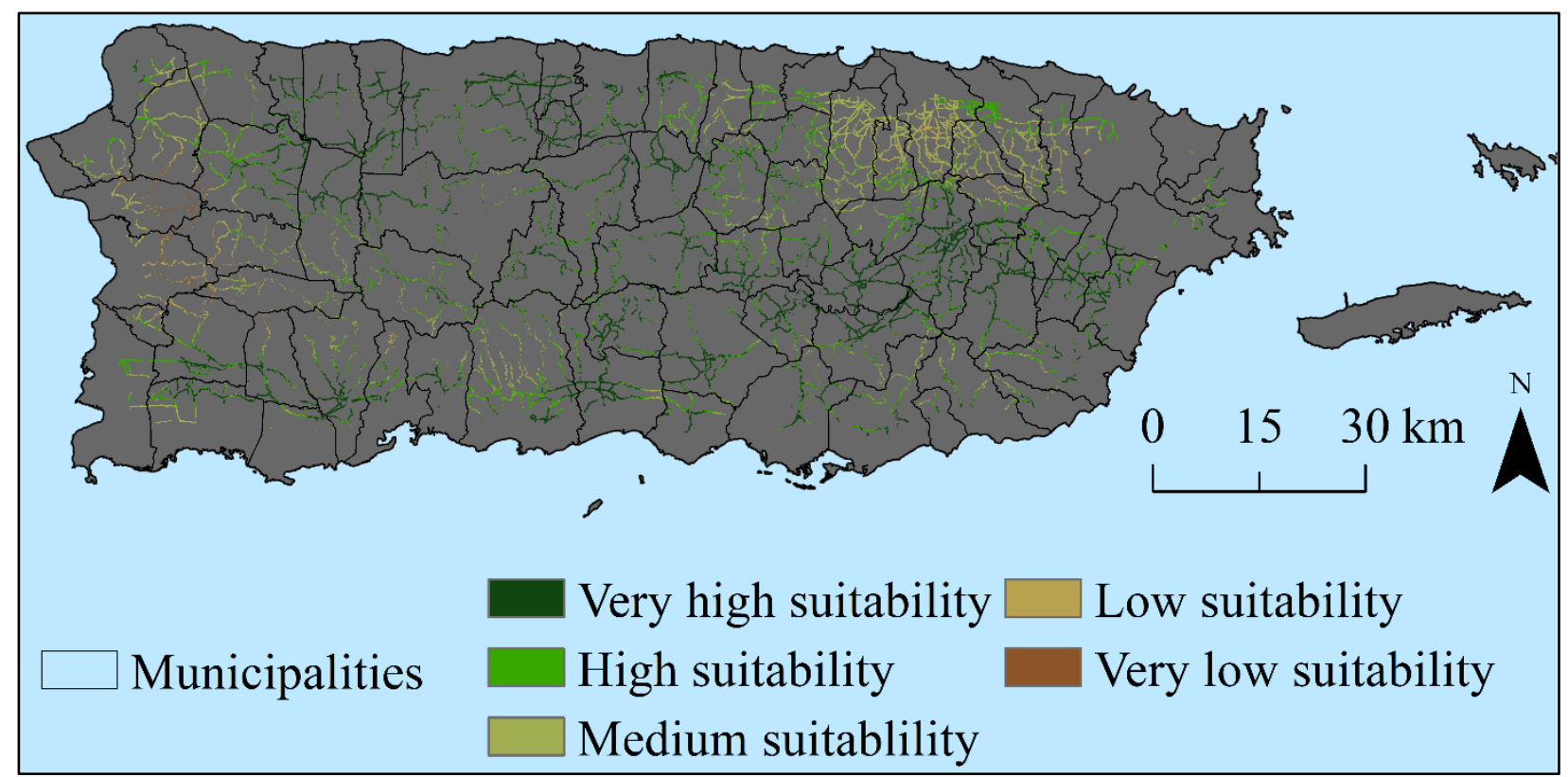

Figure 29: Suitable and accessible locations.

\section{DISCUSSIONS}

\subsection{SUITABILITY OF EXISTING POWER PLANTS AND SUBSTATIONS}

Presently, most of the powerplants, sub-stations, and transmission lines along the coastline are in hazardous locations. Proximity to the coastline presents risk of coastal flooding, which could cause substantial damage to the plants, thereby leading to extensive power loss. Given the large-scale power outage experienced during hurricane Maria, it is not surprising to find that most of the existing power stations are in unsuitable areas despite their proximity to roads and highways. Only $16 \%$ and $42 \%$ of existing power plants and sub-stations respectively are in suitable areas. This study provides information about suitable sites based on several factors that could be used to minimize risk to existing power stations and in identifying sites for placement of reserve generators that are away from hazardous areas, but close to roads. This will ensure that power supply is resumed following extreme events to meet customer demand, and help with speedy recovery and restoration of energy infrastructure. 


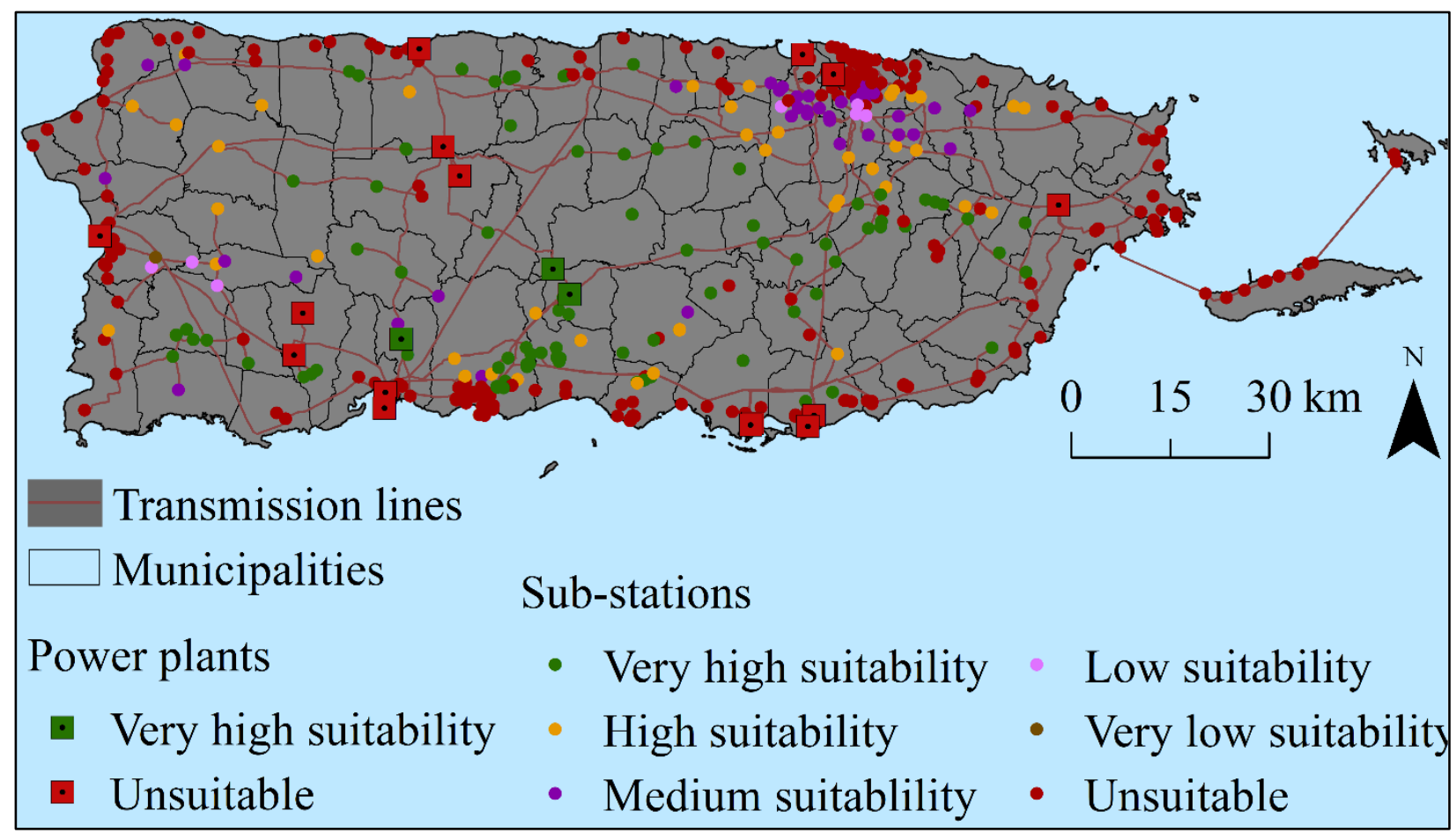

Figure 30: Site suitability of existing power plants and sub-stations.

\subsection{UTILIZING EXISTING CRITICAL FACILITIES}

Government facilities including colleges and universities, hospitals, prisons, and military bases were analyzed to determine their suitability to house energy infrastructure. Evidently, majority of these facilities are in unsuitable locations (Figure 33). Nonetheless, because these facilities have structures that could be used to house reserve generators, and these facilities could also be easily accessed via roads, they could be retrofitted to reduce risks and be used for housing reserve generators. For instance, if an existing facility is currently classified as unsuitable, and the disqualifying factor is tornado risk, tornado shelters on the site of the facility could be used for placing reserve generators. Further assessment of the indicated facilities is needed before deciding their suitability for energy infrastructure. 


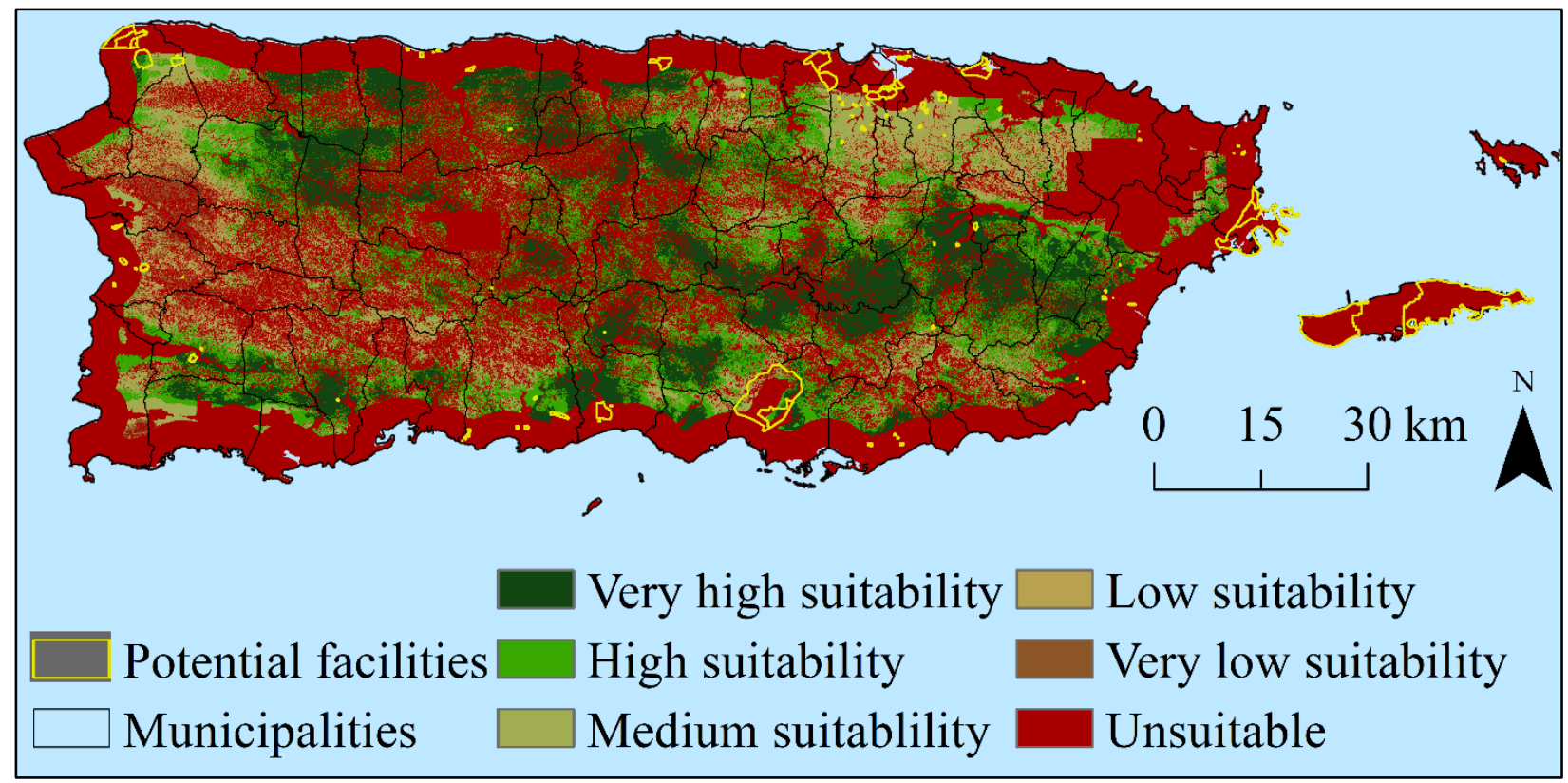

Figure 31: Suitability of potential government facilities.

Specific suitably located government facilities where reserve generators and transformers may be placed were identified. Information on the suitability level of facilities' locations based on the generated suitability map was also assessed. However, facilities currently identified as being in unsuitable locations may be considered if measures (e.g., tornado or hurricane safe shelters) are taken to mitigate potential damage from extreme events. This will require onsite surveys of the facility to determine suitability.

\subsubsection{Potential placement sites at suitably located hospitals}

Suitably located hospitals were identified and mapped (Figure 34). These can also serve as potential placement sites for reserve generators and transformers. Most of the identified hospitals are in the San Juan region although there are three hospitals each in the south eastern and south western parts of PR. 


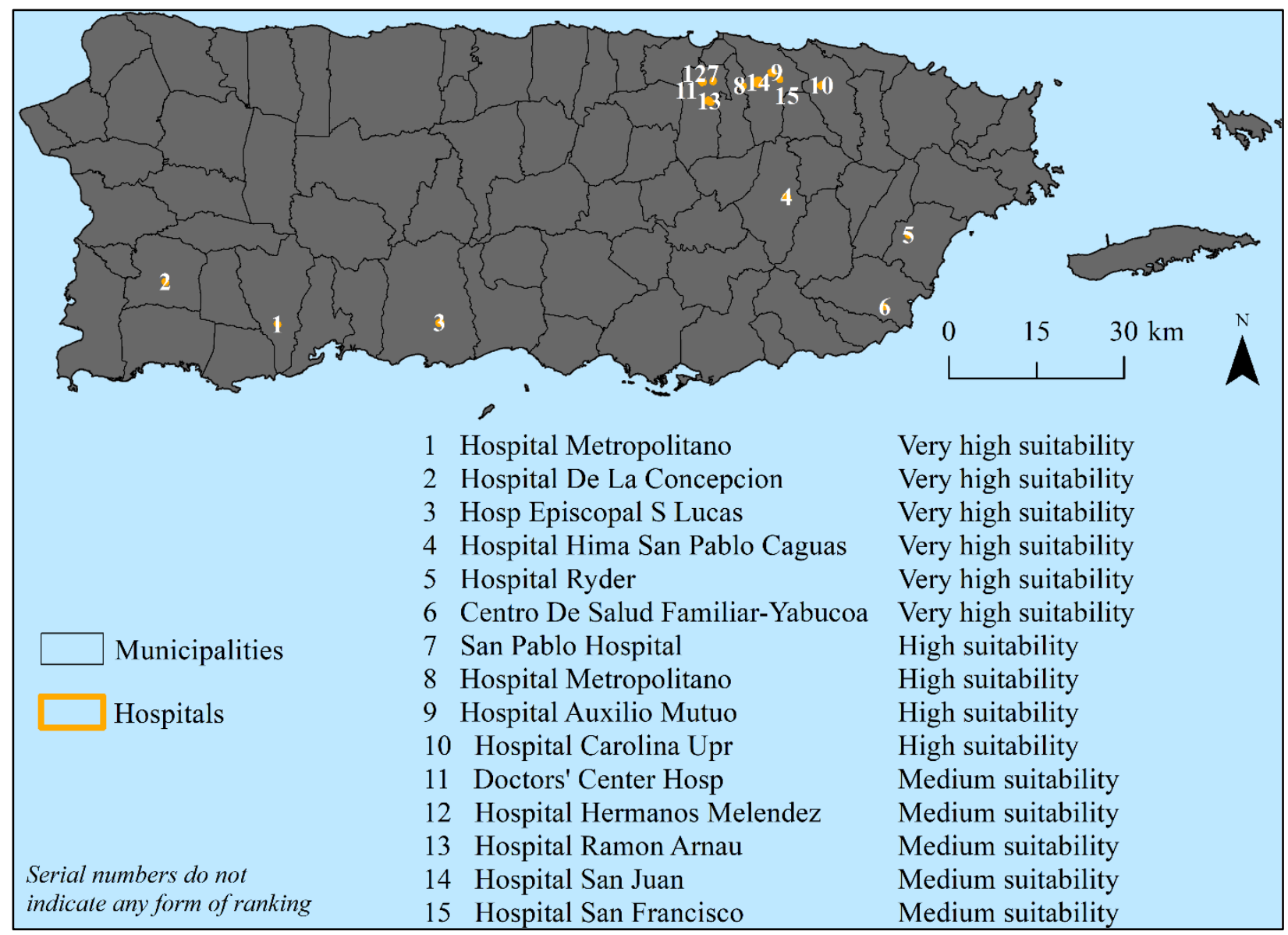

Figure 32:Potential hospitals for placement of reserve generators and transformers.

High resolution imagery acquired two days following hurricane Maria's landfall confirmed insignificant damage to Ryder Hospital which is only about 10 miles from the hurricane's path and within the strong wind field (Figure 35). 


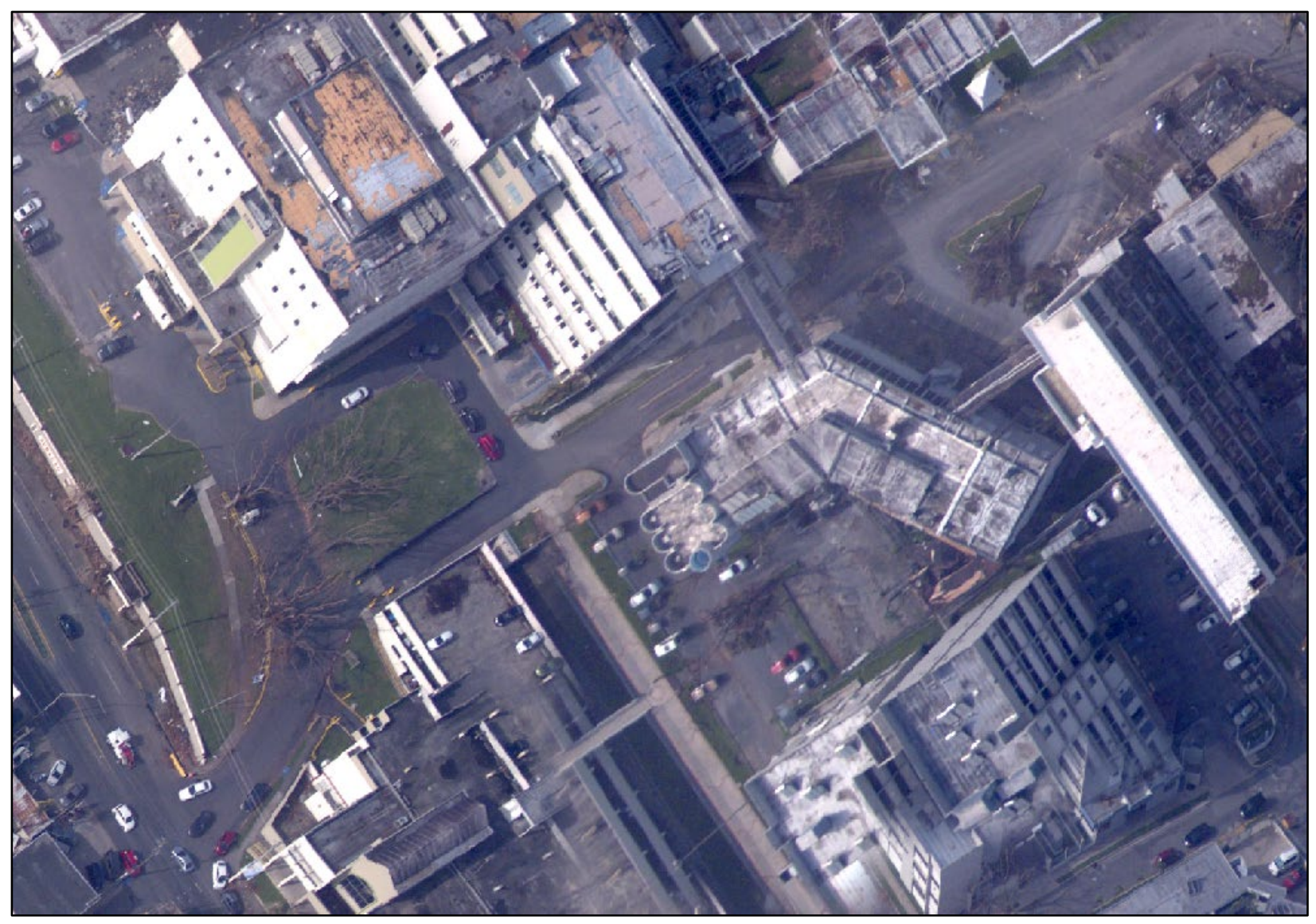

Figure 33: Satellite image showing Ryder hospital two days after hurricane Maria's landfall. 


\subsubsection{Potential placement sites at suitably located colleges and universities}

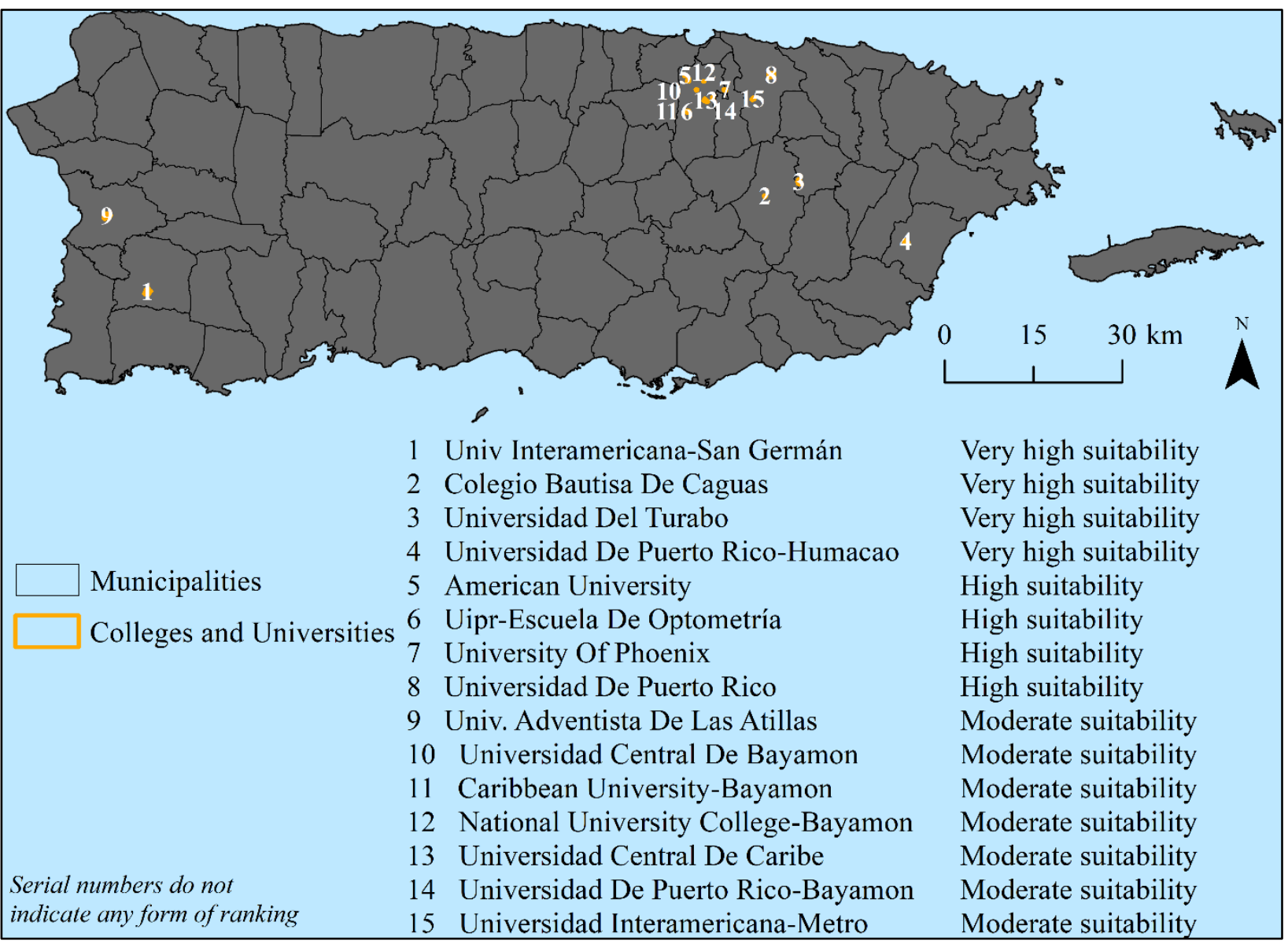

Figure 34: Potential colleges and universities for placement of reserve generators and transformers.

\subsubsection{Potential placement sites at suitably located airports}

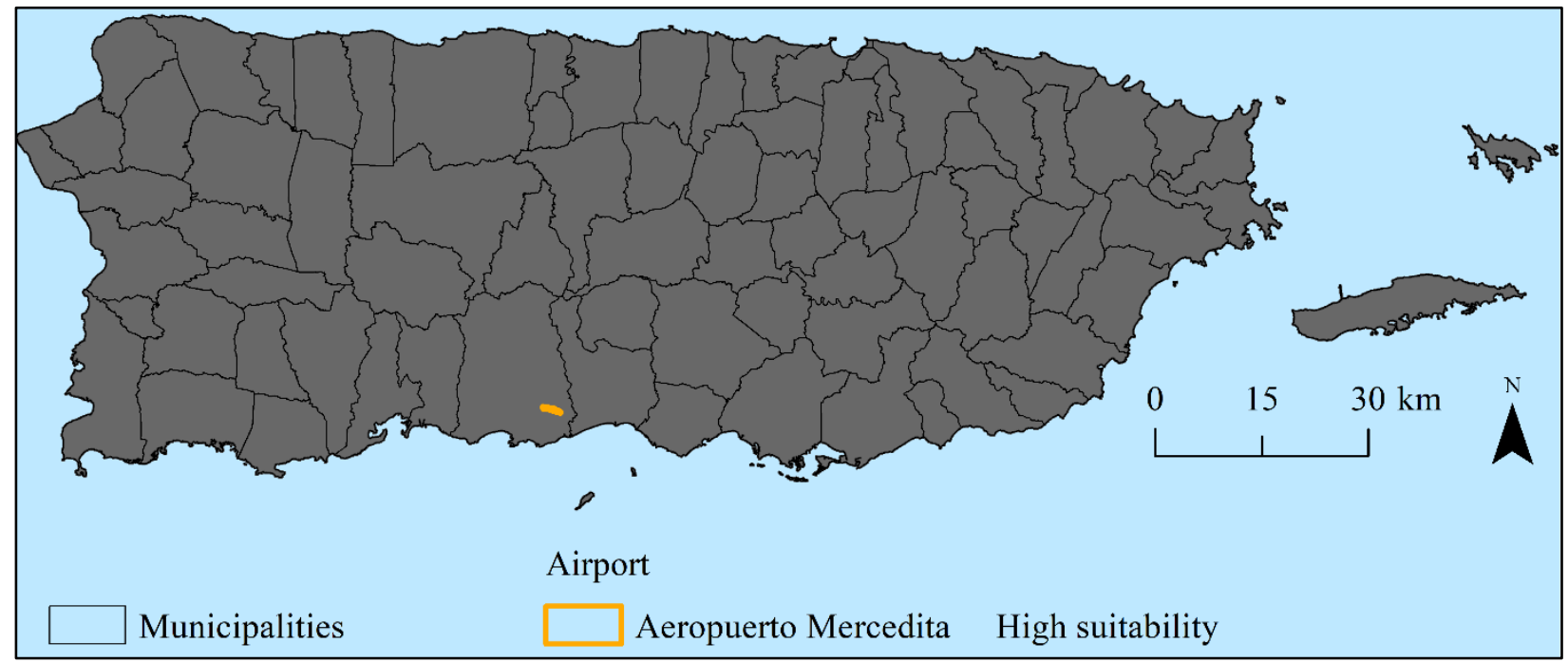

Figure 35: Potential airports for placement of reserve generators and transformers. 


\subsubsection{Potential placement sites at suitably located military bases}

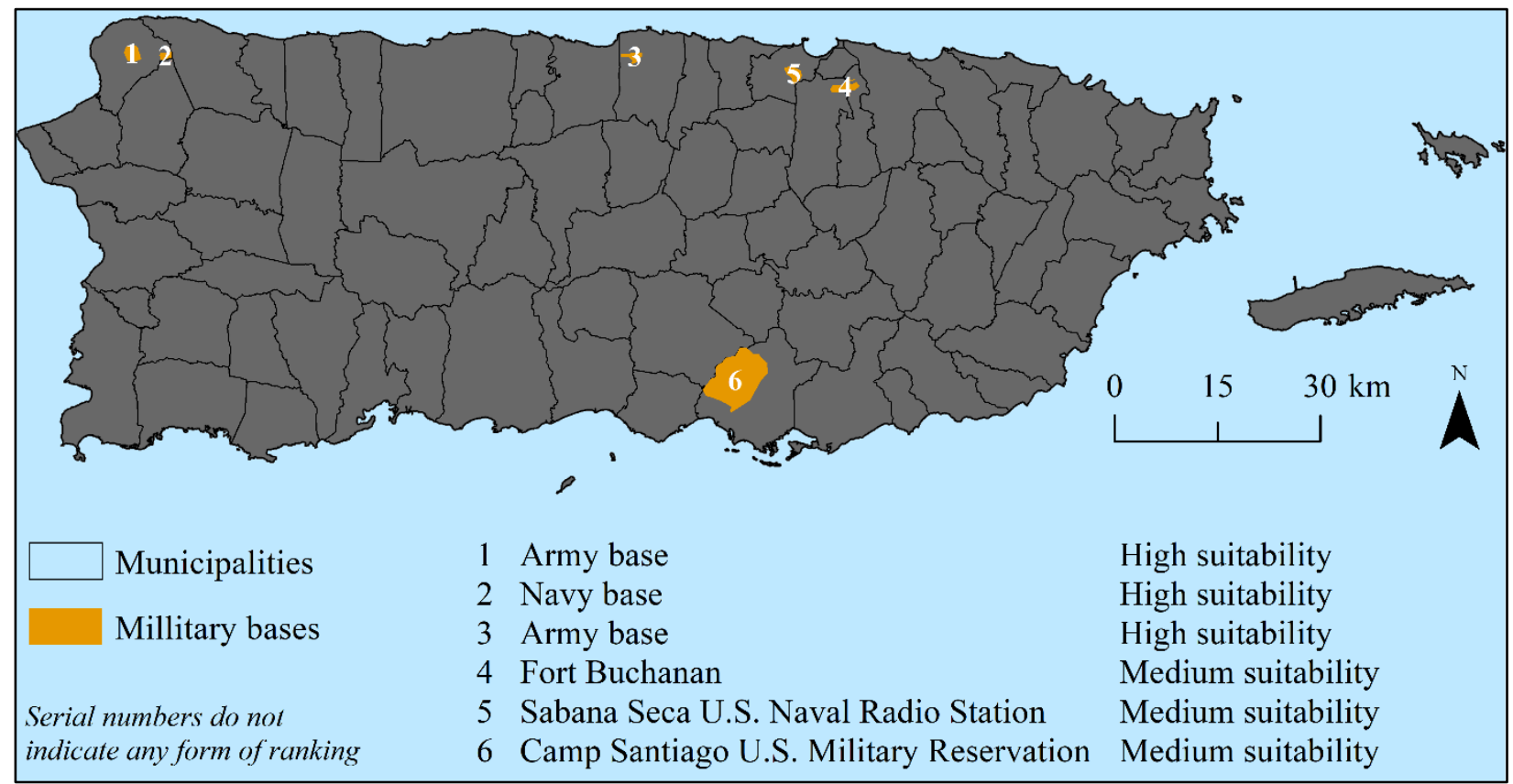

Figure 36: Potential military bases for placement of reserve generators and transformers. 


\subsubsection{Potential placement sites at suitably located correctional facilities}

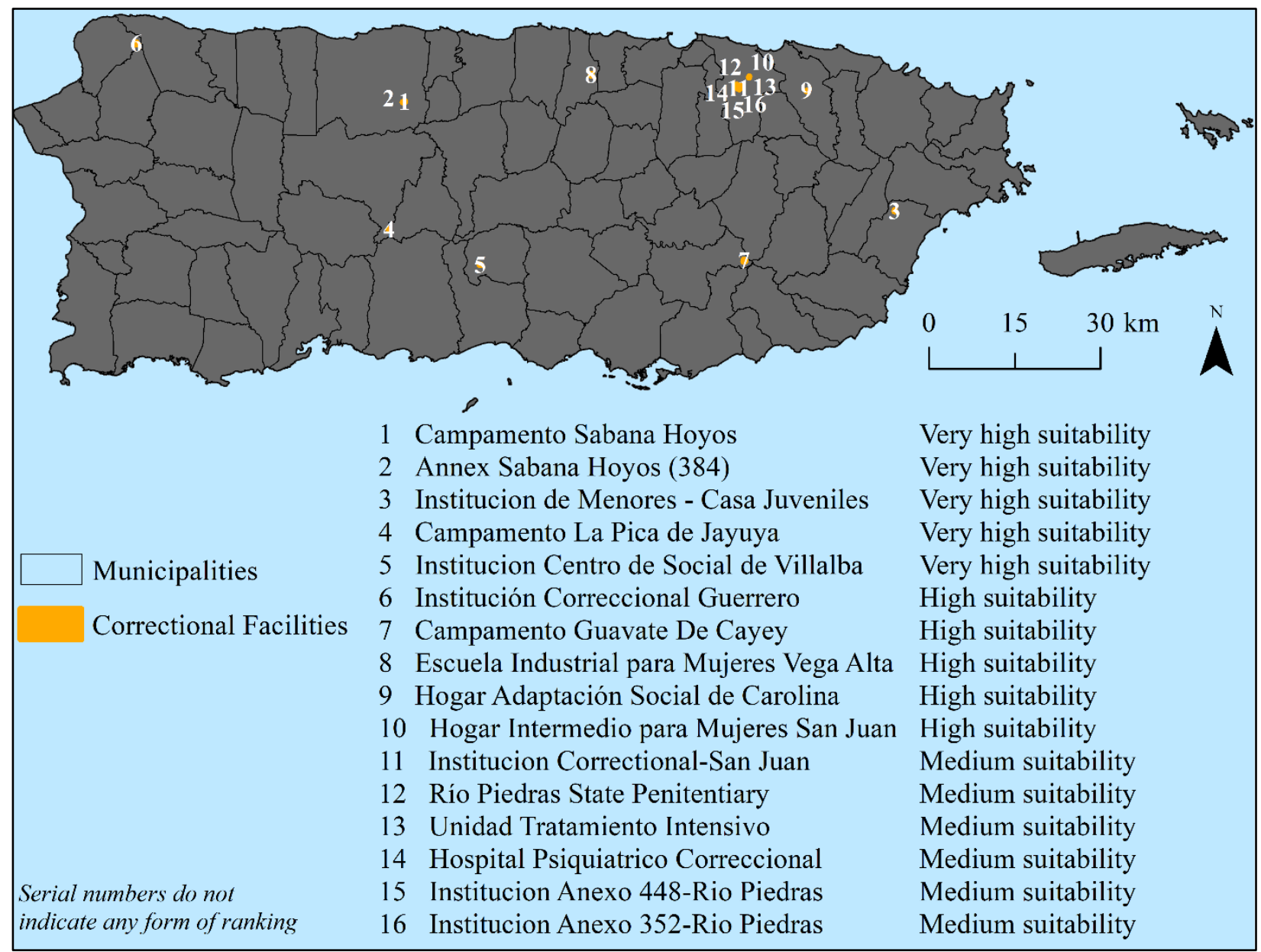

Figure 37: Potential correctional facilities for placement of reserve generators and transformers.

\subsection{ANALYZING ONLY THE VERY HIGHLY SUITABLE EXISTING FACILITIES}

Existing government facilities located within very high suitability areas are shown in Figure 38 and listed in Table 12. These include six hospitals, four colleges and universities, and five correctional facilities. Most of them are in the southern half of the island but one correctional facility is in north PR. Three hospitals are in the south western parts, and three in the south eastern parts of the island. Three colleges are in the central eastern side and only one is in the western region. Three correctional facilities are in central PR, and only one in the east. None of the facilities are in the north western or north eastern side. Available facilities (Figure 38), present the best opportunities for placement of reserve generators. For unrepresented regions, alternate facilities within lower suitability areas (high and medium) may be chosen. Otherwise suitable sites may be selected from the generated suitability map in Figure 29. 


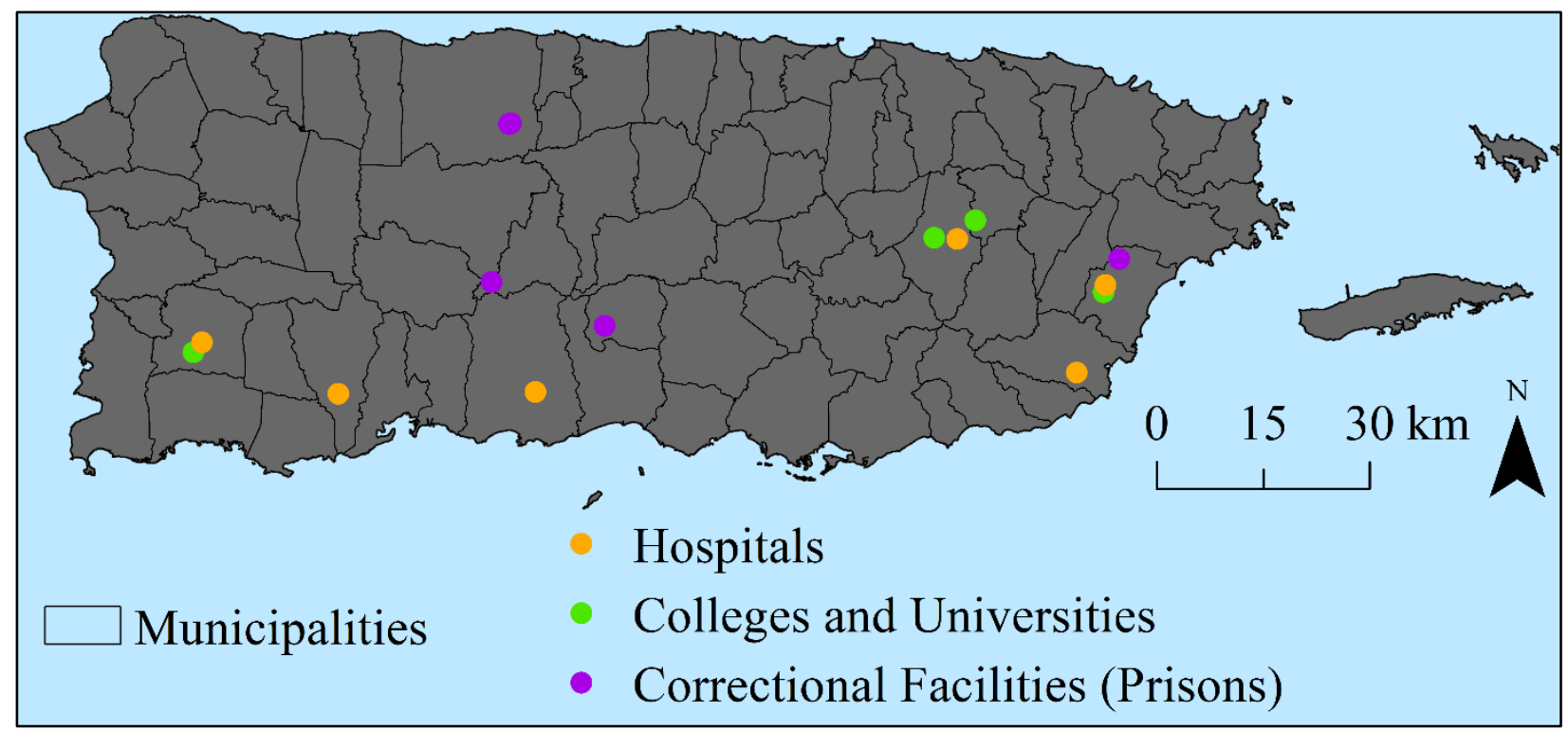

Figure 38: Existing facilities within very high suitability areas.

Refer to figures in section 6.2 for names of facilities.

Table 12: A list of existing government facilities located in very high suitability areas

\begin{tabular}{llll}
\hline Location Name & Geographic Area & Latitude & Longitude \\
\hline Hospital Metropolitano & South west & 18.031505 & -66.8578 \\
Hospital De La Concepcion & South west & 18.098815 & -67.0385 \\
Hosp Episcopal S Lucas & South & 18.030863 & -66.5954 \\
Hospital Hima San Pablo Caguas & East & 18.217701 & -66.0309 \\
Hospital Ryder & South east & 18.15585 & -65.8349 \\
Centro De Salud Familiar-Yabucoa & South east & 18.045138 & -65.8748 \\
Univ Interamericana-San Germán & South east & 18.086332 & -67.0498 \\
Colegio Bautisa De Caguas & East & 18.219682 & -66.0616 \\
Universidad Del Turabo & East & 18.240879 & -66.0064 \\
Universidad De Puerto Rico-Humacao & South east & 18.146885 & -65.8374 \\
Campamento Sabana Hoyos & South east & 18.373093 & -66.6233 \\
Annex Sabana Hoyos (384) & North & 18.372461 & -66.6256 \\
Institucion de Menores - Casa Juveniles & South east & 18.188644 & -65.8155 \\
Campamento La Pica de Jayuya & Central south & 18.171491 & -66.6516 \\
Institucion Centro de Social de Villalba & Central south & 18.113662 & -66.5019 \\
\hline \multicolumn{2}{c}{ Coordinates are in GCS WGS84 (decimal degrees) } \\
\hline
\end{tabular}

\section{CONCLUSION}

This report presents results on a site suitability assessment task for placement of generators and transformer reserves in PR. By combining all possible factors that may pose a challenge or conflict to the placement of reserve generators, potential siting areas were identified. These were ranked according to their suitability level that was based on the level of risk involved in choosing a site. All of the areas that were classified as unsuitable in the exclusion layer were found to present significant risk to the existence or challenges to installation and operation of generator and transformer reserves. These were therefore excluded from consideration as potential sites. 
Of the physical site characteristics, slope was found to present the most constraint spatially, rendering most of the central region of PR as unsuitable. Sites that present minimal risk of earthflow and less mobility challenges were considered suitable. Wetlands and floodplains susceptible to flooding pose problems to both the safety and transportation of energy equipment. In addition, proximity to the coastline exposes the potential site to probability of storm surge in case of a hurricane or tsunami. As measured against the normal high tide level, low lying areas are at even greater risk of storm surge flooding.

Natural hazards such as earthquakes, landslides, tornadoes, wind storms, and hurricanes cause the most devastating effects to energy infrastructure once they occur. This however depends on the level of risk as determined by the probability of occurrence and severity of the phenomenon. An assessment of tornado, wind, and earthquake hazard for PR based on past occurrences revealed widespread (most of the island) risk with occasional events of significance not necessarily constrained to a specific geographic location. Even so, some regions were found to have higher concentration of occurrences. Levels of site suitability were thus defined based on the density of past occurrences. Based on the result, the central western region and areas close to San Juan are at higher-risk of experiencing tornadoes, earthquakes, and strong winds. Landslides posed the greatest risk in most of central PR. This was not surprising considering the rugged terrain of the region.

Potential placement sites will ensure that reserve generators serve the maximum number of people. Most populated areas were therefore termed as most suitable while those with 0 persons within a square mile were eliminated as unsuitable. Land use restrictions on federal lands rendered all sites within protected lands as unsuitable. However, government facilities including hospitals, military bases, colleges, airports, and correctional facilities were identified as alternate potential placement sites. It was determined that these sites may have existing buildings for housing generator facilities.

The MCE technique employed combined all of the factors in a spatial environment to determine site suitability for individual locations ( $30 \mathrm{~m}$ x $30 \mathrm{~m}$ grid areas). The very highly suitable sites present the least or no constraint to placement of generator reserves while the very low suitable sites present the greatest constraint without necessarily disqualifying potential sites. More than half (55.9\%) of the PR land area was found to be unsuitable for siting generator reserves. Out of the remaining $45 \%$ of the land area, $14 \%$ are very highly suitable, $15 \%$ highly suitable, and $10 \%$ moderately suitable for locating energy facilities. Suitability analysis of existing power plants and sub-stations revealed that only $16 \%$ and $42 \%$ respectively are in suitable areas. This information may guide the placement of generator reserves close to the unsuitably placed power plants and sub-stations such that in the event of power failure because of damage to the plants, reserve generators may serve to provide power to surrounding affected customers as well as being used for restoration process of damaged facilities.

\section{REFERENCES}

Al-Shalabi, Mohamed A., Shattri Bin Mansor, Nordin Bin Ahmed, and Rashid Shiriff. 2006. "GIS Based Multicriteria Approaches to Housing Site Suitability Assessment.” In XXIII FIG Congress. Shaping the Change. Munich, Germany, October 8-13, , 1-17.

American Association of Sate Highways and Transportation Officials. 2005. A Policy on Design Standards: Interstate System. http://large.stanford.edu/courses/2014/ph240/suresh2/docs/AASHTOInterstateDesignStandards.pdf (July 16, 2018).

Basri, N A et al. 2016. "Regulatory Requirements for Nuclear Power Plant Site Selection in Malaysia-a Review." Journal of Radiological Protection 36(4): R96-111. http://stacks.iop.org/09524746/36/i=4/a=R96?key=crossref.707100c4f9cc80142d84f626f1847b6d. 
Bessette-Kirton, Erin K. et al. 2017. "Preliminary Locations of Landslide Impacts from Hurricane Maria, Puerto Rico." Map data showing concentration of landslides caused by Hurricane Maria in Puerto Rico. https://landslides.usgs.gov/research/featured/2017/maria-pr/ (July 27, 2018).

Bhaduri, Budhendra, Edward Bright, Phillip Coleman, and Marie L Urban. 2007. "LandScan USA: A High-Resolution Geospatial and Temporal Modeling Approach for Population Distribution and Dynamics." GeoJournal 69(1-2): 103-17.

Bright, Eddie A, Amy N Rose, Marie L Urban, and Jacob J McKee. 2017. "LandScan 2016." https://landscan.ornl.gov/.

Bunruamkaew, Khwanruthai, and Yuji Murayama. 2011. "Site Suitability Evaluation for Ecotourism Using GIS \& AHP: A Case Study of Surat Thani Province, Thailand." Procedia - Social and Behavioral Sciences 21: 269-78.

Federal Emergency Management Agency. 2018. Flood Risk Database (FRD) Technical Reference. https://www.fema.gov/media-library-data/15242490620408a315833d69131560239507668fa779b/Flood_Risk_Database_Technical_Reference_Feb_2018.pdf.

Idris, Rosniza, and Abd Latif Zulkiflee. 2012. "GIS Multi-Criteria for Power Plant Site Selection." Proceedings - 2012 IEEE Control and System Graduate Research Colloquium, ICSGRC 2012 (Icsgrc): 203-6.

Institute of Electrical and Electronic Engineers. 2012. IEEE Guide for the Transportation of Transformers and Reactors Rated $10000 \mathrm{kVA}$ or Higher.

Jain, Kamal, and Y. Venkata Subbaiah. 2007. "Site Suitability Analysis for Urban Development Using GIS.” Journal of Applied Sciences 7(18): 2576-83.

Kar, Bandana, and Michael E. Hodgson. 2008. "A GIS-Based Model to Determine Site Suitability of Emergency Evacuation Shelters." Transactions in GIS 12(2): 227-48.

Keeney, R. L. 1980. Siting Energy Facilities. Academic Press.

National Oceanic and Atmospheric Administration. 2017. "Severe Weather Database Files (1950-2017)." https://www.spc.noaa.gov/wcm/ (May 17, 2018).

Omitaomu, Olufemi A. et al. 2012. "Adapting a GIS-Based Multicriteria Decision Analysis Approach for Evaluating New Power Generating Sites.” Applied Energy 96: 292-301.

Smith, Michael J de, Michael F Goodchild, and Paul A Longley. 2006. Univariate Classifi Cation Schemes in Geospatial Analysis-A Comprehensive Guide. 3rd ed.

United States Geological Survey. 2015. "United States Geological Survey National Elevation Database (NED)." https://1ta.cr.usgs.gov/NED (January 11, 2018).

—. "ANSS Comprehensive Earthquake Catalog (ComCat)." Advanced National Seismic System Comprehensive Earthquake Catalog (ComCat). https://earthquake.usgs.gov/data/comcat/(July 26, 2018).

United States Nuclear Regulatory Commision. 2012. "Reactor Site Criteria." NRC Regulations (10 CFR). https://www.nrc.gov/reading-rm/doc-collections/cfr/part100/full-text.html.

Zachry, Brian C., William J. Booth, Jamie R. Rhome, and Tarah M. Sharon. 2015. "A National View of Storm Surge Risk and Inundation." Weather, Climate, and Society 7(2): 109-17. http://journals.ametsoc.org/doi/10.1175/WCAS-D-14-00049.1. 